\title{
Integrated soil fertility management in sub-Saharan Africa: unravelling local adaptation
}

\author{
B. Vanlauwe ${ }^{1}$, K. Descheemaeker ${ }^{2}$, K. E. Giller ${ }^{2}$, J. Huising ${ }^{3}$, R. Merckx ${ }^{4}$, G. Nziguheba ${ }^{1}$, J. Wendt ${ }^{5}$, \\ and S. Zingore ${ }^{6}$ \\ ${ }^{1}$ International Institute of Tropical Agriculture (IITA), Nairobi, Kenya \\ ${ }^{2}$ Plant Production Systems, Wageningen University, P.O. Box 430, Wageningen, the Netherlands \\ ${ }^{3}$ International Institute of Tropical Agriculture (IITA), Ibadan, Nigeria \\ ${ }^{4}$ Department of Earth and Environmental Sciences, Katholieke Universiteit Leuven (KU Leuven), \\ Leuven, Belgium \\ ${ }^{5}$ International Fertilizer Development Cooperation (IFDC), Nairobi, Kenya \\ ${ }^{6}$ International Plant Nutrition Institute (IPNI), Nairobi, Kenya \\ Correspondence to: B. Vanlauwe (b.vanlauwe@cgiar.org)
}

Received: 27 September 2014 - Published in SOIL Discuss.: 20 December 2014

Revised: 06 April 2015 - Accepted: 06 May 2015 - Published: 22 June 2015

\begin{abstract}
Intensification of smallholder agriculture in sub-Saharan Africa is necessary to address rural poverty and natural resource degradation. Integrated soil fertility management (ISFM) is a means to enhance crop productivity while maximizing the agronomic efficiency (AE) of applied inputs, and can thus contribute to sustainable intensification. ISFM consists of a set of best practices, preferably used in combination, including the use of appropriate germplasm, the appropriate use of fertilizer and of organic resources, and good agronomic practices. The large variability in soil fertility conditions within smallholder farms is also recognized within ISFM, including soils with constraints beyond those addressed by fertilizer and organic inputs. The variable biophysical environments that characterize smallholder farming systems have profound effects on crop productivity and $\mathrm{AE}$, and targeted application of agro-inputs and management practices is necessary to enhance AE. Further, management decisions depend on the farmer's resource endowments and production objectives. In this paper we discuss the "local adaptation" component of ISFM and how this can be conceptualized within an ISFM framework, backstopped by analysis of AE at plot and farm level. At plot level, a set of four constraints to maximum AE is discussed in relation to "local adaptation": soil acidity, secondary nutrient and micronutrient (SMN) deficiencies, physical constraints, and drought stress. In each of these cases, examples are presented whereby amendments and/or practices addressing these have a significantly positive impact on fertilizer AE, including mechanistic principles underlying these effects. While the impact of such amendments and/or practices is easily understood for some practices (e.g. the application of SMNs where these are limiting), for others, more complex processes influence $\mathrm{AE}$ (e.g. water harvesting under varying rainfall conditions). At farm scale, adjusting fertilizer applications to within-farm soil fertility gradients has the potential to increase AE compared with blanket recommendations, in particular where fertility gradients are strong. In the final section, "local adaption" is discussed in relation to scale issues and decision support tools are evaluated as a means to create a better understanding of complexity at farm level and to communicate appropriate scenarios for allocating agro-inputs and management practices within heterogeneous farming environments.
\end{abstract}




\section{Introduction}

Integrated soil fertility management (ISFM) is a means to increase crop productivity in a profitable and environmentally friendly way (Vanlauwe et al., 2010) and thus to eliminate one of the main factors that perpetuates rural poverty and natural resource degradation in sub-Saharan Africa (SSA). Current interest in ISFM partly results from widespread demonstration of the benefits of typical ISFM interventions at plot scale, including the combined use of organic manure and mineral fertilizers (e.g. Zingore et al., 2008), dualpurpose legume-cereal rotations (e.g. Sanginga et al., 2003), or micro-dosing of fertilizer and manure for cereals in semiarid areas (e.g. Tabo et al., 2007). ISFM is also aligned to the principles of sustainable intensification (Pretty et al., 2011; Vanlauwe et al., 2014a), one of the paradigms guiding initiatives to increase the productivity of smallholder farming systems. Sustainable intensification, though lacking a universally accepted definition, usually comprises aspects of enhanced crop productivity, maintenance and/or restoration of other ecosystems services, and enhanced resilience to shocks. ISFM can increase crop productivity and likely enhances other ecosystems services and resilience by diversifying farming systems, mainly with legumes, and increasing the availability of organic resources within farms, mainly as crop residues and/or farmyard manure.

One of the principles of ISFM - the combined application of fertilizer and organic resources - has been promoted since the late 1980s (e.g. Vanlauwe et al., 2001), because of (i) the failure of Green Revolution-like interventions in SSA and (ii) the lack of adoption of low-external-input technologies by smallholder farmers, including herbaceous legumebased technologies (e.g. Schulz et al., 2001). The combined application of fertilizer and organic inputs made sense since (i) both fertilizer and organic inputs are often in short supply in smallholder farming systems due to limited affordability and/or accessibility; (ii) both inputs contain varying combinations of nutrients and/or carbon, thus addressing different soil fertility-related constraints; and (iii) extra crop produce can often be observed due to positive direct or indirect interactions between fertilizer and organic inputs (Vanlauwe et al., 2001). In 1994, Sanchez (1994) presented the "second paradigm" for tropical soil fertility management, to "overcome soil constraints by relying on biological processes by adapting germplasm to adverse soil conditions, enhancing soil biological activity, and optimizing nutrient cycling to minimize external inputs and maximize their use efficiency". In this context, he already highlighted the need to integrate improved germplasm, a second principle of ISFM, within any improved strategy for nutrient management.

In 2010, with the renewed interest and investments in boosting productivity of African agriculture, following the Abuja Fertilizer Summit and the launch of the Alliance for a Green Revolution in Africa (AGRA), ISFM was reconceptualized with a focus on fertilizer use and the need for max- imizing the agronomic efficiency (AE) of its nutrients and consequently the value : cost ratio of its use. This reconceptualization was driven by the recognition that crop productivity in SSA cannot be improved substantially without enhanced fertilizer use and took into account lessons learnt with earlier approaches described above. Agronomic efficiency is defined as extra crop yield produced per unit of fertilizer nutrient applied. Maximizing AE also minimizes the risk that fertilizer nutrients move beyond the rooting zone into the environment and pollute water sources, a problem more typical for high input agriculture and less of a risk for African agriculture (Vanlauwe and Giller, 2006). In this context, applying organic resources in combination with fertilizer can enhance the $\mathrm{AE}$ of applied fertilizer through a range of direct and indirect mechanisms (Vanlauwe et al., 2001) and the use of improved germplasm is essential to ensure that the supply of nutrients is matched with an equivalent demand for those nutrients. ISFM was thus redefined as "A set of soil fertility management practices that necessarily include the use of fertilizer, organic inputs, and improved germplasm combined with the knowledge on how to adapt these practices to local conditions, aiming at maximizing agronomic use efficiency of the applied nutrients and improving crop productivity". "All inputs need to be managed following sound agronomic principles" (Vanlauwe et al., 2010). This definition includes a reference to "adaptation to local conditions". The revised conceptualization of ISFM also distinguished between responsive and non-responsive soils, both soils often occurring within the same farm and the latter being soils on which no significant response to "standard" fertilizer, or fertilizer that is commonly available and often composed of $\mathrm{N}$, $\mathrm{P}$, and/or K, can be observed (see Sect. 2 below) (Fig. 1).

This paper focuses on the "adaptation to local conditions" of ISFM. "Local adaptation" refers to specific decisionmaking processes in relation to the allocation of agro-inputs and management practices at farm and plot level, thereby recognizing production objectives, resource endowments, and farm- and field-specific soil fertility conditions. Although local adaptation was briefly discussed by Vanlauwe et al. (2010), many questions have been raised in relation to the understanding of this component of ISFM and the practices associated with it. The objectives of the paper are therefore (i) to conceptualize the local adaptation of ISFM, (ii) to illustrate the impact of alleviating secondary constraints on the fertilizer nutrient $\mathrm{AE}$ at plot scale, (iii) to illustrate the impact of farm-level targeting of inputs and practices on fertilizer nutrient $\mathrm{AE}$ at farm scale, (iv) to discuss the consequences of the above on engaging extension agents and farmers with local adaptation concepts and practices, and (v) to propose research issues that require urgent attention for ISFM to move to scale. 


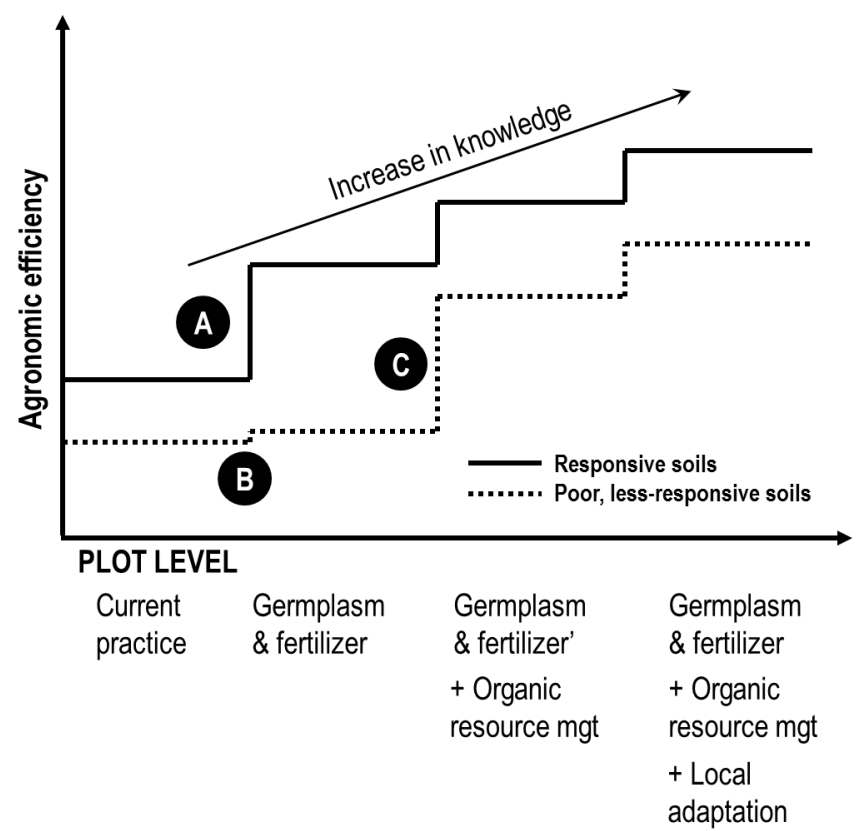

Move towards 'complete ISFM'

Figure 1. Conceptual relationship between the agronomic efficiency (AE) of fertilizers and organic resource and the implementation of various components of ISFM, culminating in complete ISFM towards the right side of the graph. Soils that are responsive to NPK-based fertilizer and those that are poor and less responsive are distinguished. Path A indicates anticipated increases in AE when fertilizer is applied using appropriate agronomic practices in combination with adapted germplasm. Paths $\mathrm{B}$ and $\mathrm{C}$ refer to the need for addressing non-responsiveness $(\mathrm{C})$ before increases in $\mathrm{AE}$ can be expected on non-responsive soils, even after application fertilizer in combination with adapted germplasm (B). Source: Vanlauwe et al. (2010).

\section{Conceptualization of local adaptation}

Since the formulation of the second paradigm (Sanchez, 1994) and with the renewed focus on making fertilizer accessible to and profitable for smallholder farmers, several insights have been gathered that influence fertilizer nutrient $\mathrm{AE}$ and thus need to be integrated in the definition of ISFM. Smallholder farming systems in SSA are very diverse, ranging from semi-nomadic pastoralism in very arid environments to shifting cultivation in the humid tropical forests. Although strongly driven by agro-ecological conditions, this diversity has also been influenced through the interplay of, amongst other things, local cultures, infrastructure, distance to markets, and socioeconomic opportunities outside agriculture. African farming areas have been described at continental scale under 13 main categories (Dixon et al., 2001), but such simplification masks huge local diversity, which makes generalization of productivity-enhancing recommendations for SSA problematic (Giller, 2013). Nevertheless, repeating patterns can be observed across different African farming systems that have important implications for ISFM.

\subsection{Patterns of soil fertility conditions within smallholder farms}

First of all, a number of factors determine the fertility of soils: (i) parent material, (ii) soil formation processes like weathering operating at a timescale of thousands of years, and (iii) human management operating over much shorter timescales. The processes of soil formation and of soil redistribution through erosion and deposition give rise to the soilscape with typical patterns of soil types associated with slope position across the landscape. Soils can be more gravelly and thinner with rock outcrops close to hill tops, with more fertile soils in mid-slope positions and fertile, alluvial soils in the valleys. Superimposed on the soilscape is a pattern created by human management. Apart from a few exceptions, such as the home-garden agroforestry systems of southern Ethiopia (Abebe et al., 2010), intensive sedentary agriculture is less than 100 years old in the majority of SSA and has been changing rapidly with very rapid growth of human population. Two opposing factors have driven the development of patterns of soil fertility (Giller et al., 2006). On the one hand, increasing pressure on land and the disappearance of fallows have led to intensive cropping which in turn depleted the soils of nutrients. On the other hand, nutrients, concentrated through manure, have been applied to part of the farm - often the fields close to the homestead. These opposing processes give rise to patterns of soil fertility, as depicted conceptually in Fig. 2. For instance, in the "ring management" pattern in West Africa, a circle of more fertile soil close to houses is surrounded by poor soils and then increasingly fertile soil with distance from the settlement as bush fields further from the village are cropped less frequently (Prudencio, 1993; Ruthenberg, 1980). In the Bukoba region of western Tanzania, cattle were used to harvest nutrients to develop fertile banana-coffee-food crop gardens (bibanja) in a sea of extensive grasslands (rweya) (Baijukya et al., 2005). The reasons that farmers concentrate their nutrient resources on the home fields are manifold: the home field provides grain for the food security of the household, nutrient resources are often in short supply and insufficient to apply to all of the fields, the home fields are less susceptible to theft, and it is more convenient and requires less labour to transport manure (Misiko et al., 2011).

Fertile home fields need only maintenance fertilization to sustain good crop yields, and crop response to fertilizer in strongly depleted soils is often weak due to a suite of nutrient deficiencies (Fig. 3; Vanlauwe et al., 2006). For example, on depleted outfields on sandy granitic soils in Zimbabwe, crop response to $\mathrm{N}$ and $\mathrm{P}$ fertilizers was limited by deficiencies of $\mathrm{Zn}, \mathrm{Ca}, \mathrm{Mg}$, and $\mathrm{K}$ (Zingore et al., 2008). Such depleted fields have been described as "non-responsive soils", or soils that have been degraded to an extent that the application of 

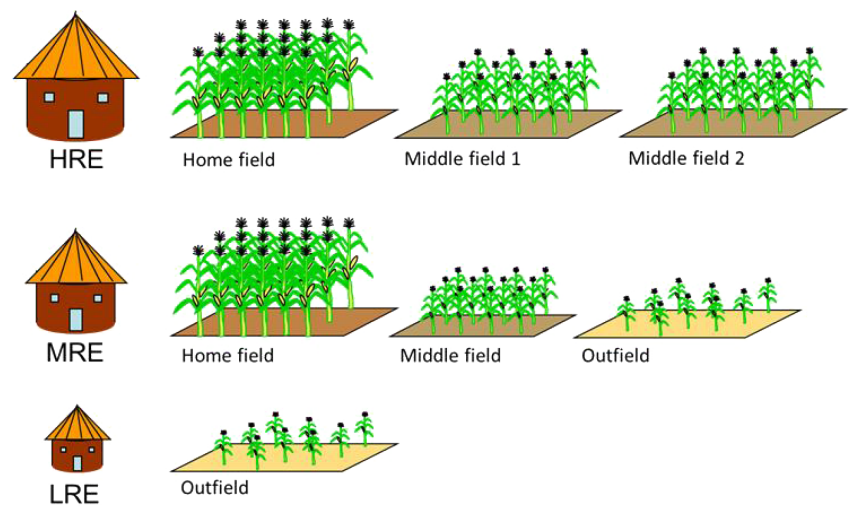

Figure 2. High-resource-endowed farms (HRE) tend to have more cattle and manure and can maintain good soil fertility and crop yields across all of their fields. Low-resource-endowed farms (LRE) have no livestock and manure and their fields are often uniformly poor in soil fertility and crop yields. Farmers of intermediate resource endowment (MRE) have limited resources that they apply preferentially to the home fields, creating strong gradients of soil fertility. This allows the classification of fields across the different farms into three types: fertile home fields, moderately fertile middle fields, and poorly fertile outfields for three farmer typologies (HRE, MRE, and LRE) (cf. Zingore et al., 2007a).

NPK fertilizer does not result in increased crop productivity (Vanlauwe et al., 2010). Such soils are common in densely populated areas where mineral and/or organic inputs are in short supply and the generation of non-responsiveness can be a combination of chemical (e.g. soil acidification, micronutrient deficiencies), physical, (e.g. topsoil erosion, hardpan formation), and/or biological (e.g. soil-borne pests and diseases) mechanisms. Obviously, the AE of fertilizer nutrients applied on non-responsive soils is very low to zero and crop yield increases agronomically and/or economically insignificantly.

\subsection{Farmer typologies, resource endowments, and production objectives within smallholder farming communities}

A second commonly observed pattern is the diversity of resource endowments and farm types within farming communities (Fig. 2; Tittonell et al., 2010). Drivers operating at different scales generate a diversity of farming households in relation to available on- and off-farm resources and production objectives. Whereas relatively poor families often cultivate more degraded soils (Tittonell and Giller, 2013), families with a relatively higher resource endowment have more options to purchase and allocate fertilizer and organic inputs across the various plots within their farms. The latter are also usually less risk-averse and thus more open to explore alternative agricultural practices within their farm. Soil fertility gradients are often clearest on farms of intermediate resource endowment, as conceptually depicted in Fig. 2.

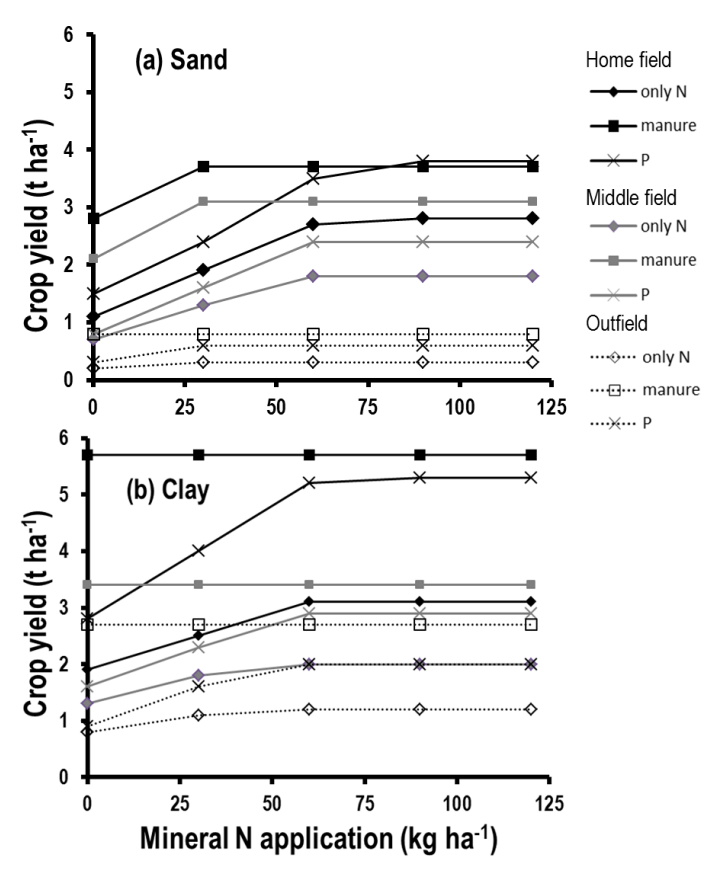

Figure 3. Simulated crop yield with the model FIELD as a function of mineral $\mathrm{N}$ application rates for different soil fertility zones on sand (a) and clay (b) soils and nutrient management options (only mineral $\mathrm{N}$, manure at $10 \mathrm{tha}^{-1}$ and mineral $\mathrm{N}$, and mineral $\mathrm{P}$ at $20 \mathrm{~kg} \mathrm{ha}^{-1}$ and mineral N) (refer to Zingore et al., 2011, for a detailed soil characterization and description of the FIELD model).

Besides access to resources, farmers have different production objectives. For instance, in western Kenya, Tittonell et al. (2005) identified that some small farms were owned by wealthy households which had external income from pensions or remittances and for whom farming is not their primary income. Such households are not expected to consider agricultural investments a priority. In contrast, well-resourceendowed farmers with large areas of land make a relatively good living from farming. Poor households with very small farms have limited access to resources, often selling their labour to other households, and are thus expected to apply fewer or no agro-inputs on their farms.

\subsection{Limitations of improved germplasm and organic resources to maximize fertilizer $\mathrm{AE}$}

Organic resources can enhance the $\mathrm{AE}$ of fertilizer nutrients through a number of mechanisms, including "direct" (e.g. temporary $\mathrm{N}$ immobilization) and "indirect" interactions (e.g. temporary alleviation of soil acidity constraints and supply of other yield-limiting nutrients) (Vanlauwe et al., 2001). Improved germplasm can equally enhance AE of fertilizer nutrients by ensuring a higher demand for applied nutrients. For certain constraints, however, organic resource application and improved germplasm are not a suitable solution and other amendments or practices are required (Table 1). 
Table 1. A selected set of constraints that can prevent the uptake of nutrients applied with "standard" fertilizer - or fertilizer that is commonly available and often composed of N, P, and/or K - and the potential of improved germplasm, organic resources, and other amendments and/or soil management practices to alleviate these constraints.

\begin{tabular}{|c|c|c|}
\hline Constraint & $\begin{array}{l}\text { Potential of improved germplasm and organic resources } \\
\text { and specific traits required }\end{array}$ & $\begin{array}{l}\text { Other amendments or soil management prac- } \\
\text { tices }\end{array}$ \\
\hline $\begin{array}{l}\text { Soil acidity resulting in } \\
\text { large amounts of } \\
\text { exchangeable } \mathrm{Al}\end{array}$ & $\begin{array}{l}\text { Limited and short term - organic inputs with high de- } \\
\text { composability, and preferably concentrated around the } \\
\text { planting hole }\end{array}$ & $\begin{array}{l}\text { Application of lime (calcite or dolomite) } \\
\text { depending on } \mathrm{Ca}: \mathrm{Mg} \text { ratios and target crops }\end{array}$ \\
\hline $\begin{array}{l}\text { Secondary nutrient de- } \\
\text { ficiencies }\end{array}$ & $\begin{array}{l}\text { Limited - high-quality species are required to supply a } \\
\text { sufficient amount of secondary nutrients; high-quality } \\
\text { manure may contain sufficient secondary nutrients }\end{array}$ & Application of multi-nutrient fertilizer \\
\hline Drought stress & $\begin{array}{l}\text { Limited - surface mulch with low quality (e.g. high } \\
\text { lignin content and } \mathrm{C}: \mathrm{N} \text { ratio) can reduce evaporation } \\
\text { and enhance soil moisture availability }\end{array}$ & $\begin{array}{l}\text { Water harvesting techniques (e.g. zaï, tied } \\
\text { ridges) can substantially increase water avail- } \\
\text { able for crops }\end{array}$ \\
\hline Hardpan formation & $\begin{array}{l}\text { Limited - some deep-rooting trees or grasses may } \\
\text { facilitate crop root growth }\end{array}$ & Deep tillage \\
\hline Surface sealing & $\begin{array}{l}\text { Appropriate - surface mulch inhibits the formation of } \\
\text { surface sealing }\end{array}$ & Surface tillage \\
\hline $\begin{array}{l}\text { Striga hermonthica } \\
\text { damage }\end{array}$ & $\begin{array}{l}\text { Appropriate - use of crops triggering suicidal germina- } \\
\text { tion of Striga; surface mulch reduces Striga emergence }\end{array}$ & $\begin{array}{l}\text { Use of Striga-tolerant/resistant varieties in } \\
\text { combination with integrate Striga management } \\
\text { options }\end{array}$ \\
\hline
\end{tabular}

For instance, removing a hardpan that restricts crop root growth will require deep ploughing in most cases (though in some cases, the use of deep-rooting trees or grasses could be a solution) (Amézquita et al., 2004; Vanlauwe et al., 2005). For instance, alleviating soil acidity constraints beyond a single season can only be achieved through the incorporation of the right amount and quality of lime. Many observations support positive interactions between water and nutrient management practices (Bationo et al., 1998). While in situations with moisture stress, water harvesting practices certainly fit under local adaptation, improved germplasm (e.g. droughttolerant germplasm) and organic resource management (e.g. surface mulch to reduce evaporation) can also assist in alleviating drought-related constraints. The same applies to other constraints reducing the AE of fertilizer nutrients (Table 1).

Additional practices or agro-inputs that can alleviate constraints not addressed through improved varieties, fertilizer, or organic inputs require integration in the ISFM definition. While the efficient use of fertilizer and organic resources is a principle that is universally applicable - because removing crops requires nutrients to be replenished and applied organic inputs mineralize their carbon over time - other constraints are often observed over geographically limited areas and do not require attention everywhere and all of the time. Thus, such additional practices or agro-inputs are integrated under the local adaptation component of ISFM, operating at plot scale (Fig. 4). Secondly, at farm scale, farming households make decisions on where to invest their available resources (capital, labour) within their heterogeneous farms and aligned to their production objectives, risk aversion, and resource endowment. Local adaptation thus also refers to decisions and recommendations in relation to the types and quantities of agro-inputs and how these are allocated at farm scale (Fig. 4).

With the concept of local adaptation within ISFM having been discussed, the following sections provide quantitative information on how decisions and practices embedded within local adaptation impact on the $\mathrm{AE}$ of fertilizer nutrients.

\section{Impact of local adaptation interventions at plot scale on the agronomic efficiency of fertilizer nutrients}

This section presents evidence from SSA related to the impact of soil amendments or practices other than introduction of improved varieties or organic resource application on the $\mathrm{AE}$ of fertilizer nutrients. Most of the evidence relates to $\mathrm{N}$ fertilizer applied to maize as (i) $\mathrm{N}$ is the most limiting nutrient in many African soils, and (ii) most research on ISFM has focused on maize. We present a set of case studies that illustrate the potential impact of plot-level interventions on fertilizer AE. We do not aim to present a comprehensive literature review or meta-analysis but rather elaborate the mechanistic interactions between amendments and practices and the $\mathrm{AE}$ of fertilizer nutrients. Although many constraints could be considered, we focus on four: soil acidity, secondary nutrient limitations, physical constraints, and drought stress. 


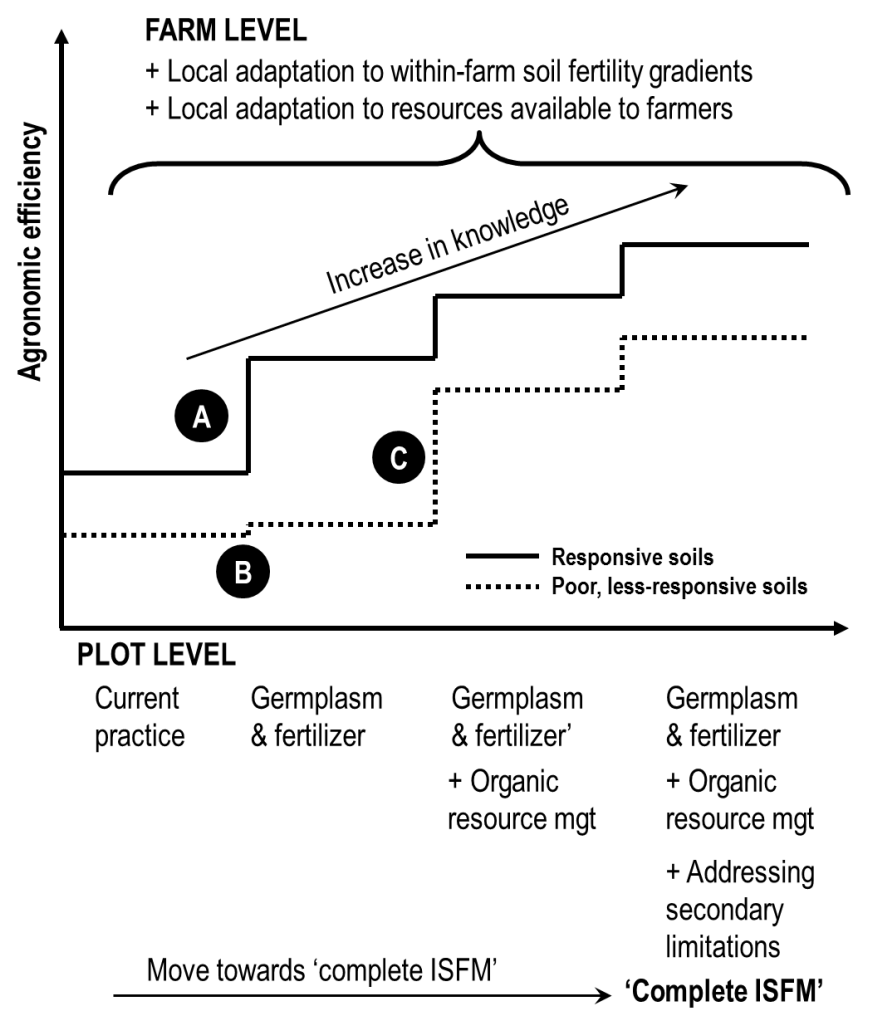

Figure 4. Revised conceptual framework underlying integrated soil fertility management (ISFM), adapted from the original version, presented by Vanlauwe et al. (2010). The current version distinguished plot from farm-level local adaptation interventions.

\subsection{Liming effects on fertilizer $\mathrm{AE}$}

Especially in the high-rainfall humid zones of SSA, soil acidity and more specifically the presence of relatively high amounts of exchangeable aluminium (Al) is a severe constraint to crop productivity. Some strongly weathered soils are inherently acidic, such as Ferralsols or Acrisols, occupying about $15 \%$ of agricultural land in SSA (www.fao.org), while others, such as Arenosols or Lixisols, occupying about $27 \%$ of agricultural land in SSA (www.fao.org), are prone to acidification due to inappropriate management practices such as the application of ammonium-containing fertilizer in absence of crop residue recycling. Al toxicity rather than soil acidity per se is considered to be the major concern of acid soils because it reduces the availability of various nutrients (e.g. P, $\mathrm{Ca}, \mathrm{Mg}$ ) and inhibits root growth of most plants, thus limiting nutrient uptake. In order to improve the productivity of acid soils, exchangeable and soluble $\mathrm{Al}$ contents need to be reduced. While acid soils may be managed in several ways, including the use of crop species that are tolerant to high levels of exchangeable $\mathrm{Al}$ or concentrating relatively high levels of organic resources near the planting hole (Cong and Merckx, 2005), liming is the most established means for correcting Al toxicity (The et al., 2006; Crawford et al.,

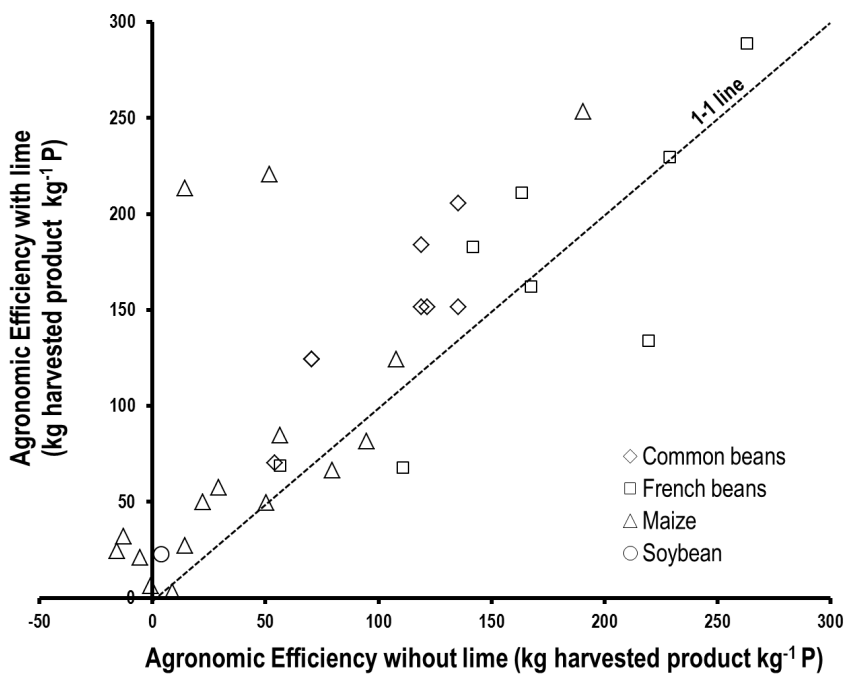

Figure 5. Agronomic efficiency of $\mathrm{P}$ fertilizer in the presence or absence of lime application, expressed as extra kilograms of grain harvested per kilogram of P fertilizer (or extra kilograms of fresh pods per kilogram of $\mathrm{P}$ fertilizer in the case of French beans). Data are adapted from case studies conducted in Kenya (Barasa et al., 2013; Gudu et al., 2005; Mbakaya et al., 2011), Cameroon (The et al., 2006), Burundi (ISABU, unpublished; IFDC, PAN-PSNEB project), and Ethiopia (Legesse et al., 2013).

2008). However, management of Al toxicity has received little attention in recent years in SSA, mainly because (i) $\mathrm{Al}$ toxicity is believed to be localized to only a particular few areas of central Africa where highly weathered and leached soils occur (Crawford et al., 2008) and (ii) the use of lime has been constrained by limited infrastructure for mining lime deposits and transporting the final product.

It has been demonstrated that liming increases the efficiency of fertilizers mainly by (i) increasing the availability of nutrients through favouring processes that govern nutrient release and availability in the soil solution and (ii) enhancing root growth. As for $\mathrm{N}$, plants absorb most $\mathrm{N}$ in nitrate $\left(\mathrm{NO}_{3}^{-}\right)$ form and the transformation of ammonium $\left(\mathrm{NH}_{4}^{+}\right)$to $\mathrm{NO}_{3}^{-}$, commonly known as nitrification, is $\mathrm{pH}$-dependent, becoming severely reduced at $\mathrm{pH}$ below 5 . This reduction in nitrification results not only in decreased $\mathrm{N}$ availability for plant uptake (Crawford et al., 2008) but also in reduced risk for $\mathrm{N}$ leaching with $\mathrm{NO}_{3}^{-}$being much more prone to leaching beyond the crop rooting zone. Overall, the efficiency of $\mathrm{N}$ fertilizers is expected to be reduced at low soil $\mathrm{pH}$, while liming a soil with a $\mathrm{pH}$ below 5 stimulates the nitrification process, favouring $\mathrm{N}$ availability and ultimately $\mathrm{N}$ AE (von Uexkull, 1986; Crawford et al., 2008). High levels of exchangeable Al reduce the availability of $\mathrm{P}$ by precipitating or adsorbing $\mathrm{P}$ (Uchida and Hue, 2000; Von Uexkull, 1986). Liming reduces $\mathrm{P}$ adsorption, resulting in an increase in $\mathrm{P} \mathrm{AE}$ upon liming, as demonstrated by a number of trials in East and Central Africa (Fig. 5). 
In conclusion, appropriate liming practices are expected to increase the agronomic efficiency of fertilizers on soils exhibiting high levels of exchangeable Al by favouring processes towards increased nutrient availability and uptake. Even though lime deposits are available in most countries affected by $\mathrm{Al}$ toxicity, the cost effectiveness of lime application, especially in relation to transport and the commonly required high application rates, is likely to negatively affect the adoption of this practice.

\subsection{Secondary nutrient effects on fertilizer AE}

Secondary and micronutrients (SMNs), including $\mathrm{Ca}, \mathrm{Mg}, \mathrm{S}$, $\mathrm{Zn}, \mathrm{Cu}, \mathrm{Mn}, \mathrm{Fe}, \mathrm{B}$, and $\mathrm{Mo}$, often limit crop growth, especially in soils are continuously cropped without returning these nutrients. Most of the commonly applied fertilizer in SSA contains mainly $\mathrm{N}, \mathrm{P}$, and/or $\mathrm{K}$, which do not replenish SMNs. Nutrient depletion can be further aggravated by soil acidification, which interferes with the availability of specific nutrients. The considerable extent of SMN deficiencies in SSA is gradually becoming apparent. The Ethiopian Soil Information Service is currently involved in mapping the entire country for all nutrients, and has found extensive areas of S, Zn, and B deficiency (www.africasoils.net/EthioSIS). Soil nutrient maps of Rwanda and Burundi show that the majority of the arable land is affected by multiple nutrient deficiencies, including $\mathrm{P}, \mathrm{Ca}, \mathrm{Mg}, \mathrm{S}, \mathrm{Zn}$, and $\mathrm{B}$, as well as low soil pH (www.ifdc.org/Nations/Rwanda/; www.ifdc. org/Nations/Burundi/). Significant maize responses to S (e.g. Wendt and Rijpma, 1997; Weil and Mughogho, 2000), Mg (e.g. Abunyewa and Mercer-Quarshie, 2004), Zn (e.g. Abunyewa and Mercer-Quarshie, 2004; Zingore et al., 2008), Cu (e.g. Lisumu et al., 2006), and B (Wendt and Rijpma, 1997) have been demonstrated across the continent.

Application of secondary and micronutrients can have significant effects on crop yields in sub-Saharan Africa (Table 2), but has received less attention than the macronutrients $\mathrm{N}, \mathrm{P}$, and $\mathrm{K}$, as illustrated by the fact that most fertilizer subsidy programmes primarily focus on NPK fertilizers. This may be due in part to a commonly expressed belief that there is no need to address other nutrients while the continent is still struggling to adopt macronutrient fertilizers. But indeed the reverse is more likely to be true: where SMN deficiencies exist, they can limit response to NPK fertilizers. Because SMNs are required in small quantities, addressing these deficiencies can offer farmers an increased return on fertilizer investment, which is a major factor in increasing farmer adoption. One shortcoming of much research on SMN deficiencies in sub-Saharan Africa is that SMNs are often investigated individually, rather than in combination. Multiple rather than individual SMN deficiencies are the norm in much of sub-Saharan Africa. In an omission trial from Burundi (average of 16 sites), attainable yields with balanced nutrient application were $>5 \mathrm{Mtha}^{-1}$ but eliminating either $\mathrm{Cu}$ or $\mathrm{B}$ limited the response of all other nutrients to

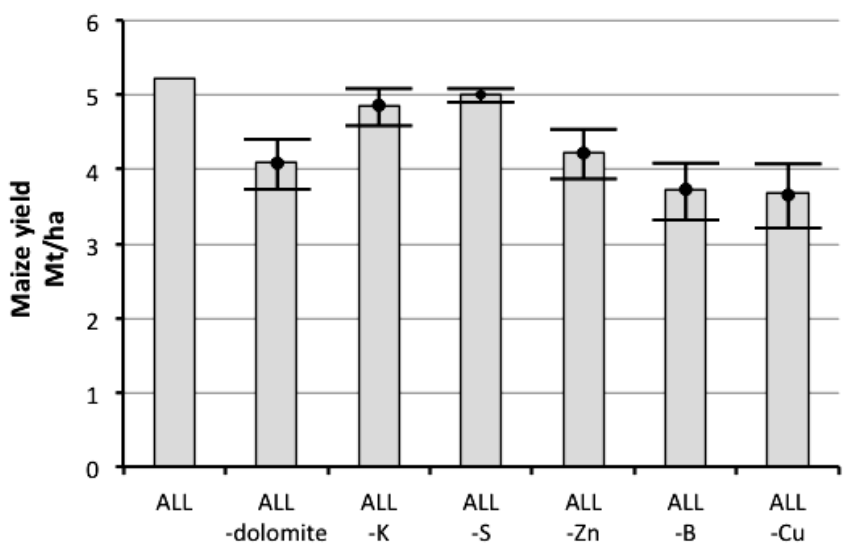

Figure 6. Maize yield response to omission of various secondary and micronutrients in Burundi (average of 16 sites). An "ALL" treatment consists of all likely deficient nutrients and included (per hectare) $750 \mathrm{~kg}$ dolomite (Ca+Mg lime), $71 \mathrm{~kg} \mathrm{~N}, 20 \mathrm{~kg} \mathrm{P}, 25 \mathrm{~kg} \mathrm{~K}$, $10 \mathrm{~kg} \mathrm{~S}, 3 \mathrm{~kg} \mathrm{Zn,} 1 \mathrm{~kg} \mathrm{~B}$ (all soil-applied), and $0.25 \mathrm{~kg} \mathrm{Cu}$ (applied as a foliar spray). Each subsequent treatment omits one nutrient. A decline in yield due to the omission of that nutrient indicates its relative contribution to yield. Error bars represent the $95 \%$ confidence interval on differences between omission treatments (ALLdolomite, ALL-K, etc.) and ALL treatment as determined by paired $t$ test. All differences are significant at the $5 \%$ level.

3.7 $\mathrm{Mtha}^{-1}$, demonstrating the importance of including all potentially deficient nutrients in an omission trial (Fig. 6). However, trials that examine response to multiple nutrients are few and far between.

In conclusion, in those countries in Africa where SMNs have been extensively mapped, multiple SMN deficiencies are the norm rather than the exception. Application of SMNs on soils exhibiting secondary nutrient limitations is an effective way to enhance fertilizer nutrient $\mathrm{AE}$, provided that all limiting nutrients are addressed. Blending commonly available NPK fertilizer with SMNs is a cost-effective process to achieve these benefits.

\subsection{Tillage effects on fertilizer AE}

Physical constraints can impede crop yield response to fertilizer and reduce $\mathrm{AE}$, mainly by reducing seed germination and root development and limiting water availability through surface crusting, soil compaction, and/or hardpan formation. Hard-setting soils that may also show surface crusting and that are prone to plough-pan formation are common in SSA (Kayombo and Lal, 1993). These characteristics are associated with light-textured soils with mainly $1: 1$ clay minerals (e.g. kaolinite) and low organic carbon content, typical, e.g. for Lixisols, which occupy approximately $10 \%$ of the cultivable land in SSA (Jones et al., 2013). The deterioration of topsoil physical properties has been associated with mechanically tilled soil in the absence of organic residue retention. Kayombo and Lal (1993), for instance, advocated zero tillage 
Table 2. Cereal yield response in various African countries due to secondary and micronutrient additions. Source: IFDC (unpublished).

\begin{tabular}{|c|c|c|c|c|c|c|}
\hline \multirow[t]{2}{*}{ Crop } & Country & $\begin{array}{r}\text { Number of } \\
\text { sites }\end{array}$ & $\begin{array}{r}\text { Yield with } \mathrm{NP}(\mathrm{K}) \\
\text { only }\end{array}$ & $\begin{array}{r}\text { Yield with NP(K) } \\
\text { and with secondary/ } \\
\text { micronutrients }\end{array}$ & $\begin{array}{r}\text { Yield increase } \\
\pm 95 \% \text { confidence } \\
\text { interval }\end{array}$ & \multirow[t]{2}{*}{$\begin{array}{l}\text { Additional } \\
\text { nutrients }\end{array}$} \\
\hline & \multicolumn{5}{|c|}{$\mathrm{tha}^{-1}$} & \\
\hline Maize & Ethiopia & 9 & 5.60 & 6.72 & $1.12 \pm 0.84$ & S, Zn, B \\
\hline Wheat & Ethiopia & 43 & 3.99 & 5.28 & $1.29 \pm 0.25$ & $\mathrm{~S}, \mathrm{Zn}, \mathrm{B}, \mathrm{Cu}$ \\
\hline Maize & Burundi & 44 & 3.11 & 5.27 & $2.16 \pm 0.29$ & Dolomite*, S, Zn, B, Cu \\
\hline Rice & Burundi & 168 & 4.89 & 6.89 & $2.00 \pm 0.12$ & $\mathrm{~S}, \mathrm{Zn}, \mathrm{B}, \mathrm{Cu}$ \\
\hline Maize & Mozambique & 17 & 2.99 & 4.18 & $1.19 \pm 0.10$ & $\mathrm{Mg}, \mathrm{S}, \mathrm{Zn}, \mathrm{B}$ \\
\hline Wheat & Rwanda & 40 & 4.14 & 5.64 & $1.50 \pm 0.25$ & $\mathrm{~K}, \mathrm{~S}, \mathrm{Zn}, \mathrm{B}, \mathrm{Cu}$ \\
\hline Rice (paddy) & Rwanda & 20 & 4.32 & 5.89 & $1.57 \pm 0.31$ & $\mathrm{~S}, \mathrm{Zn}, \mathrm{B}, \mathrm{Cu}$ \\
\hline
\end{tabular}

* Dolomite contributes both $\mathrm{Ca}$ and $\mathrm{Mg}$, in addition to reducing soil acidity.

with mulch as the most effective method for controlling soil compaction and erosion, especially for humid and sub-humid tropical environments.

In SSA, the discussion on tillage effects is intrinsically linked to the debate on conservation agriculture (e.g. Giller et al., 2009; Vanlauwe et al., 2014b), which uses minimal or zero-tillage as one of its principles. Zero or minimum tillage aims at minimizing soil disturbance, reducing soil erosion, improving water infiltration and improving soil structure (aggregate stability), all of which potentially improve fertilizer AE. In the "step trials", conducted by Thierfelder et al. (2013) in Mozambique, Malawi, Zimbabwe, and Zambia, which compared minimum tillage, with or without crop residue retention, these practices did not improve fertilizer $\mathrm{N}$ AE (Table 3). Rather, minimum tillage in these experiments resulted in considerably lower yields compared to the conventional tillage treatment $(23 \%$ for the non-fertilized plots and $13.6 \%$ yield reduction on the fertilized minimum-tillage plots). Reduced yields under minimum tillage are commonly observed, especially when no mulch is applied. In western Kenya, for instance, Paul et al. (2013) showed an average yield reduction of $19.8 \%$ on fertilized zero-tillage plots with no mulch applied, relative to tilled plots, with yield reduction limited to $3.8 \%$ with application of mulch. Similar trends were observed from experiments conducted in Zimbabwe (Mupangwa et al., 2012). Claims of longer-term positive effects of reduced tillage on yield and possibly AE cannot be substantiated. Rusinamhodzi et al. (2011), in a metaanalysis across 26 long-term field studies from around the world, found no evidence of increased maize yields under zero tillage compared with conventional tillage during the first 10 years of cropping. They did find a positive effect of reduced tillage with mulch in low rainfall environments on light-textured soils, a situation very common in southern Africa.

Some physical constraints for crop production can be alleviated by improved tillage methods. Mechanical loosening of the soil is an important method for controlling soil compaction in both humid and sub-humid and semi-arid and
Table 3. Agronomic efficiency of fertilizer $\mathrm{N}$ applied in treatments with tillage, zero tillage without residue retention, and zero tillage with residue applied retention. At each location and season the trials were carried out in four or five sub-locations and replicated four times for each sub-location. In Malawi and Mozambique, land preparation in the tillage treatments was by hand hoe, and in Zimbabwe and Zambia land was prepared using the mouldboard plough. Planting was done using a dibble stick and residue was applied at rates of 2.5 to $3 \mathrm{tha}^{-1}$. Adapted from Thierfelder et al. (2013).

\begin{tabular}{|c|c|c|c|c|}
\hline \multirow[t]{3}{*}{ Country } & \multirow[t]{3}{*}{ Location and season } & \multicolumn{3}{|c|}{$\mathrm{N}$ fertilizer agronomic efficiency } \\
\hline & & $\begin{array}{l}\text { With } \\
\text { tillage }\end{array}$ & $\begin{array}{l}\text { Zero } \\
\text { tillage }\end{array}$ & $\begin{array}{r}\text { Zero tillage, } \\
\text { residue } \\
\text { retention }\end{array}$ \\
\hline & & \multicolumn{3}{|c|}{$\mathrm{kg}$ grain $\mathrm{kg}^{-1}$ fertilizer $\mathrm{N}$} \\
\hline Malawi & Balaka 2008/09 & 20.7 & $\mathrm{NA}^{1}$ & 19.3 \\
\hline Malawi & Balaka 2009/10 & 24.5 & 19.3 & 37.8 \\
\hline Malawi & Balaka 2010/11 & 19.2 & 4.8 & 8.5 \\
\hline Malawi & Chitedze 2009/10 & 25.8 & 24.7 & 28.0 \\
\hline Malawi & Chitedze 2010/11 & 35.8 & 41.8 & 35.2 \\
\hline Mozambique & Barua 2008/09 & 4.2 & NA & 8.9 \\
\hline Mozambique & Barua 2009/10 & 20.0 & 24.8 & 18.0 \\
\hline Mozambique & Barua 2010/11 & 24.6 & 28.2 & 41.3 \\
\hline Zimbabwe & Hwedza 2009/10 & 11.1 & 13.1 & 12.5 \\
\hline Zimbabwe & Hwedza 2010/11 & 6.3 & 4.6 & 7.7 \\
\hline Zimbabwe & Murehwa 2009/10 & 18.4 & 15.9 & 14.3 \\
\hline Zambia & Monze 2010/11 & 20.8 & 25.3 & 26.6 \\
\hline Mean $^{2}$ & & 20.7 & 20.3 & 23.0 \\
\hline
\end{tabular}

arid regions of Africa, with a reportedly substantial effect on grain yield, and even more so with deep ripping and subsoiling compared with a mouldboard plough (Kayombo and Lal, 1993). Deep tillage or sub-soiling can result in a strong increase in AE of fertilizer nutrients. Chaudhary et al. (1985) showed an increase in $\mathrm{AE}$ of fertilizer $\mathrm{N}$ obtained on a loamy sand by ploughing to $20 \mathrm{~cm}$ using a mouldboard plough, subsoiling at $40 \mathrm{~cm}$ depth using a one-tine sub-soiler, and deep digging to $45 \mathrm{~cm}$ depth, compared with a disk harrower and tine cultivator alone (Table 4). This effect was more pronounced under irrigated conditions, indicating improved nu- 
Table 4. Improvement of agronomic efficiency of fertilizer $\mathrm{N}$ resulting from various deep tillage techniques compared to harrowing only (adapted from Chaudhary et al., 1985).

\begin{tabular}{lrcr}
\hline & \multicolumn{2}{c}{$\begin{array}{c}\text { Change in agronomic efficiency of fertilizer N } \\
\text { in relation to a conventionally managed treatment }\end{array}$} \\
\cline { 2 - 4 } & \multicolumn{3}{c}{$\mathrm{kg} \mathrm{grain} \mathrm{kg}^{-1} \mathrm{~N}$} \\
\hline & $\begin{array}{r}\text { No irrigation } \\
\text { Irrigation }\end{array}$ & Irrigation \\
\hline Mouldboard plough & 1981 & 1981 & 1982 \\
Sub-soiling & 8.4 & 6.0 & 18.2 \\
Deep digging & 9.4 & 13.7 & 19.1 \\
\hline
\end{tabular}

trient and water use efficiencies as a result of better root development.

In conclusion, reduced tillage does not consistently lead to yield increases, thus not improving fertilizer nutrient AE. In the longer term, reduced tillage practices can have a positive effect on infiltration and water holding capacity, but only if accompanied by application of mulch, and more so under drier conditions. On the other hand, for compacted soils, deep tillage, or sub-soiling can improve fertilizer nutrient AE.

\subsection{Water harvesting effects on fertilizer $A E$}

Inter- and intra-seasonal rainfall patterns are often irregular and pose another constraint to enhanced fertilizer uptake by crops. With climate change, within- and between-season variability in rainfall has increased in recent years (Morton, 2007). While most papers dealing with water harvesting techniques focus on the obvious positive effects on water use efficiency, the few papers addressing nutrient or fertilizer $\mathrm{AE}$ mostly pointed to elevated $\mathrm{AE}$ values, irrespective whether these are soil-, organic-residue-, or fertilizer-derived (Table 5). Most often these effects are interpreted as the indirect effect of the better moisture conditions on improved rooting density, improved nutrient mobility in the rooting zone, and a higher microbial activity releasing additional nutrients from soil organic matter or crop residues and manure.

In a small number of papers, some less expected effects emerge. Jensen et al. (2003) highlighted the negative effect that water harvesting techniques may have on fertilizer nutrient $\mathrm{AE}$ during relatively wet growing seasons. Tied ridging under these conditions apparently reduced fertilizer $\mathrm{N}$ recovery. Most likely this was due to either nitrogen losses through denitrification or restrained root activity due to periods of waterlogging. Mashingaidze et al. (2013) observed no significant effects of basin water harvesting techniques on $\mathrm{N}$ AE in a wet season. In both of these studies clear benefits were observed during the more usual weather patterns, entailing periods of drought and water stress. Besides water harvesting techniques, adjusting $\mathrm{N}$ applications to season rainfall patterns is another means to reduce nutrient losses 
and improve fertilizer nutrient $\mathrm{AE}$ in semi-arid areas (Piha, 1993).

In conclusion, in most situations with drought stress, water harvesting techniques are expected to increase fertilizer nutrient $\mathrm{AE}$, while in relatively wet seasons, such techniques can actually reduce AE. Obviously, the added costs - especially labour costs - need to be weighed against the expected increases in agronomic efficiency.

\section{Impact of local adaptation interventions at farm scale on the agronomic efficiency of fertilizer nutrients}

This section provides insights in how allocation of resources at farm scale affects farm-level fertilizer nutrient $\mathrm{AE}$ values and how household resource endowment interacts with the decision-making processes regarding the allocation of these resources and the ultimate impact on $\mathrm{AE}$ values.

\subsection{Impact of soil fertility gradients and resource endowment on farm-level productivity and $\mathrm{AE}$ : a case study from Zimbabwe}

At the farm scale, AE is influenced by a number of interdependent factors, including soil type, landscape position, soil fertility status, and allocation of nutrients. Zingore et al. (2011) investigated the optimal nutrient allocation strategy to maximize maize production at the farm level, taking into account soil fertility gradients and differences in land, livestock, and nutrient resource availability between farm types in Murewa, Zimbabwe. Differences in field-level $\mathrm{AE}$, which were related to soil texture, past management and current nutrient (N, P, manure) application, dictated where resources should be directed preferentially to maximize returns. This was done by targeting the fields where the highest AE could be achieved, based on field-level crop growth simulation results (Fig. 3). On sandy soils, whole-farm production could be maximized by concentrating the available manure on the soils of medium fertility, while mineral $(\mathrm{N}$, P) fertilizer was used most efficiently on the homestead fields (Table 6), where the high soil organic matter content ensures good growth conditions and nutrient availability, at least in the short term. This only applied to high- and medium-resource-endowed households since low-resourceendowed households did not have such soils. In the long term, the breakdown of organic matter led to a decrease in whole-farm production based on the same input levels. On clay soils, where soil organic matter is better protected against decomposition compared to sandy soils, high yields could be achieved without mineral fertilizer on both home fields and middle fields if manure was applied at high rates $\left(10 \mathrm{tha}^{-1}\right)$ (Fig. 3). Without manure input, the relatively stable soil organic matter of home and middle fields still ensured high agronomic efficiency of mineral fertilizer (Fig. 3, Table 6). Therefore, for both high- and medium-resource-
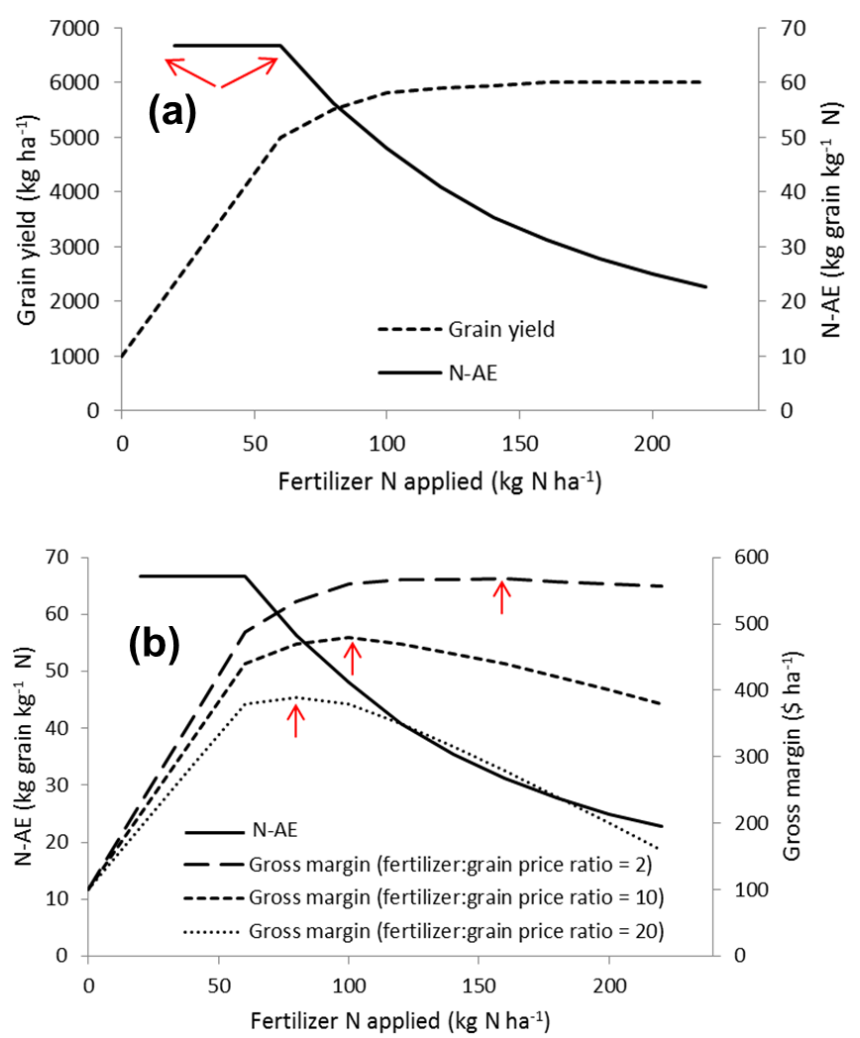

Figure 7. Relationships between fertilizer $\mathrm{N}$ application and grain yield, agronomic efficiency for nitrogen ( $\mathrm{N}$ AE) (a), and gross margin for different fertilizer: grain price ratios (b). Gross margins are calculated as: grain yield $\left(\mathrm{kg} \mathrm{ha}^{-1}\right) \cdot$ grain price $\left(\mathrm{USD} \mathrm{kg}^{-1}\right)$ - fertilizer $\mathrm{N}$ rate $\left(\mathrm{kg} \mathrm{ha}^{-1}\right)$. fertilizer cost (USD kg ${ }^{-1}$ ). Optimal fertilizer rates for maximum fertilizer N AE (range between diagonal arrows in a) and maximum gross margin (vertical arrows in b) are indicated (based on Vanlauwe et al., 2011).

endowed farmers it was most efficient to separate the allocation of manure and mineral fertilizer. Thanks to the higher inherent soil fertility and slower organic matter breakdown of clay soils, the long-term whole-farm production did not decrease as strongly as on sandy soils. High-, medium,- and low-resource-endowed farms produce different grain quantities due to differences in cultivated land area, in patterns of soil fertility and in available manure quantity. Furthermore, the optimal allocation scenario for scarce nutrient resources varied according to soil type, and also according to resource endowment (Table 6). For example, mediumresource-endowed farmers could maximize their farm-level production and agronomic efficiency by ignoring outfields and concentrating their nutrient resources to home and middle fields. Low-resource-endowed farmers, who only own outfields, could still increase their production by applying mineral fertilizers to these poor fields.

Across soil and farm types, the targeted allocation of nutrient resources resulted in equal or higher farm production and overall $\mathrm{AE}$ than the blanket recommendation (Table 6). 
Table 6. Optimal nutrient allocation scenarios versus blanket recommendation* with their resulting short- and long-term (after 10 years) maize production and agronomic efficiency for $\mathrm{N}$ fertilizer (AE_N) for a farm with typically high (HRE), medium (MRE), and low (LRE) resource endowment on a sandy and clayey soil in Murewa, Zimbabwe. M: manure application rate (tha ${ }^{-1}$ ); $\mathrm{P}, \mathrm{N}$ : mineral P, N application rate $\left(\mathrm{kg} \mathrm{ha}^{-1}\right)$; fertility zones and typical farms as described in Zingore et al. (2011).

\begin{tabular}{|c|c|c|c|c|c|c|c|c|c|c|c|c|c|c|}
\hline & & \multicolumn{7}{|c|}{ Optimal allocation scenario } & \multicolumn{6}{|c|}{ Blanket recommendation } \\
\hline & & \multirow[b]{2}{*}{ Area (ha) } & \multicolumn{3}{|c|}{ Sand } & \multicolumn{3}{|c|}{ Clay } & \multicolumn{3}{|c|}{ Sand } & \multicolumn{3}{|c|}{ Clay } \\
\hline & & & M & $\mathrm{P}$ & $\mathrm{N}$ & M & $P$ & $\mathrm{~N}$ & M & $\mathrm{P}$ & $\mathrm{N}$ & M & $\mathrm{P}$ & $\mathrm{N}$ \\
\hline \multirow[t]{6}{*}{ HRE } & Home field & 1 & 0 & 20 & 60 & 10 & 0 & 0 & 3.3 & 10 & 30 & 3.3 & 10 & 30 \\
\hline & Middle field 1 & 1 & 5 & 0 & 20 & 0 & 20 & 60 & 3.3 & 10 & 30 & 3.3 & 10 & 30 \\
\hline & Middle field 2 & 1 & 5 & 0 & 20 & 0 & 0 & 40 & 3.3 & 10 & 30 & 3.3 & 10 & 30 \\
\hline & Short-term production $(t)$ & & \multicolumn{3}{|c|}{7.7} & \multicolumn{3}{|c|}{10.5} & \multicolumn{3}{|c|}{6.9} & \multicolumn{3}{|c|}{8.4} \\
\hline & Long-term production $(t)$ & & \multicolumn{3}{|c|}{6.2} & \multicolumn{3}{|c|}{10.2} & \multicolumn{3}{|c|}{4.7} & \multicolumn{3}{|c|}{7.8} \\
\hline & Farm AE_N $\left(\mathrm{kg} \mathrm{kg}^{-1} \mathrm{~N}\right)$ & & \multicolumn{3}{|c|}{30} & \multicolumn{3}{|c|}{22} & \multicolumn{3}{|c|}{30} & \multicolumn{3}{|c|}{22} \\
\hline \multirow[t]{6}{*}{ MRE } & Home field & 1 & 0 & 20 & 90 & 0 & 20 & 70 & 2 & 10 & 30 & 2 & 10 & 30 \\
\hline & Middle field & 0.5 & 10 & 0 & 20 & 10 & 0 & 0 & 2 & 10 & 30 & 2 & 10 & 30 \\
\hline & Outfield & 1 & 0 & 0 & 0 & 0 & 0 & 30 & 2 & 10 & 30 & 2 & 10 & 30 \\
\hline & Short-term production $(t)$ & & \multicolumn{3}{|c|}{5.4} & \multicolumn{3}{|c|}{8.0} & \multicolumn{3}{|c|}{4.5} & \multicolumn{3}{|c|}{6.7} \\
\hline & Long-term production $(t)$ & & \multicolumn{3}{|c|}{4.5} & \multicolumn{3}{|c|}{7.4} & \multicolumn{3}{|c|}{3.4} & \multicolumn{3}{|c|}{6.2} \\
\hline & Farm AE_N $\left(\mathrm{kg} \mathrm{kg}^{-1} \mathrm{~N}\right)$ & & \multicolumn{3}{|c|}{29} & \multicolumn{3}{|c|}{36} & \multicolumn{3}{|c|}{25} & & 21 & \\
\hline LRE & Outfield & 1 & 0 & 20 & 30 & 0 & 20 & 60 & 0 & 10 & 30 & 0 & 10 & 30 \\
\hline & Short-term production $(t)$ & & & 0.6 & & & 2.0 & & & 0.3 & & & 1.4 & \\
\hline & Long-term production $(t)$ & & & 0.3 & & & 1.8 & & & 0.1 & & & 1.2 & \\
\hline & Farm AE_N $\left(\mathrm{kg} \mathrm{kg}^{-1} \mathrm{~N}\right)$ & & & 13 & & & 20 & & & 3 & & & 20 & \\
\hline
\end{tabular}

* It is assumed that HRE, MRE, and LRE farms have manure in varying quantities of 10,5 , and $0 \mathrm{t}$ of manure respectively, which is related to herd sizes. All farms have an equal total of $100 \mathrm{~kg}$ of $\mathrm{N}$ and $20 \mathrm{~kg}$ of $\mathrm{P}$ in the form of mineral fertilizers, meant to represent effects of an equal subsidy scheme. In the optimal allocation scenario, the nutrient resources are applied to fields where the highest agronomic efficiency can be achieved, based on Fig. 3, and by avoiding oversupply of nutrients. The blanket recommendation consists of spreading manure and applying $10 \mathrm{~kg} \mathrm{Pha}^{-1}$ and $30 \mathrm{~kg} \mathrm{Nha}^{-1}$, a typical recommendation by extension services. In some cases the blanket recommendation exceeds the total fertilizer amount at farmers' disposal.

This benefit of targeted allocation was more pronounced on medium-resource-endowed farms (Table 6), where withinfarm soil fertility gradients were strongest (Fig. 2). Especially on the sandy soils, higher N AE was achieved by exploiting the soil fertility that has been built up over many years of preferential manure allocation on the home fields. This was done by concentrating most of the mineral fertilizer on the home fields, and allocating the manure on the middle fields. Continuing this over several years, however, would result in a decrease in the soil organic matter content (cf. Rowe et al., 2006), reducing soil fertility and the farm grain production potential (Table 6). Nevertheless, with current farm management (including crop residue removal for livestock feeding) and nutrient constraints, large yield reductions on sandy soils cannot be avoided, due to the net depletion of nutrients and organic matter in these farming systems.

\subsection{Production objectives, management intensity, and fertilizer AE}

Superimposed on the soil fertility gradients are the impacts of differential management. In addition to provision of manure, livestock provide animal traction that can ensure timely ploughing and weeding. Shortage of labour leads to delays in farm operations (e.g. planting, weeding), which cause strong reductions in AE. Field experiments and simulation modelling indicated, for the example of Malawian smallholders, that weeding twice could double the $\mathrm{AE}$ of $\mathrm{N}$ as opposed to weeding once (Kamanga et al., 2014). To earn an income to purchase food, poorer households often work for wealthier farmers during periods of peak labour demand, leading to delays in crop management and therefore poorer yields in their own fields, as well as food insecurity (Kamanga et al., 2014). Thus, the above-mentioned soil fertility gradients run in parallel with gradients of management intensity (Giller et al., 2006; Tittonell et al., 2007a). For a case study farm in western Kenya, Tittonell et al. (2007b) investigated the trade-offs associated with labour and nutrient allocation strategies for varying degrees of investment. In this area of relatively high agricultural potential, allocating most labour and cash resources to the average-fertility fields allowed for the trade-off between food production and resource conservation to be minimized. Also, the optimal range of labour and nutrient allocation strategies was wide with less investment, but narrowed with increasing cash availability, explaining to some degree the large diversity of farm management and structure in smallholder farming systems. This example from Kenya illustrates that, on top of the soil fertility gra- 
dients, farm management decisions, influenced by farmers' objectives and production orientation, create another layer of complexity determining $\mathrm{AE}$ at the farm level.

Because resources (land, nutrients, labour, cash) are limited on smallholder farms, their allocation to a particular farm component or on a particular moment in time, creates trade-offs between multiple objectives operating at different timescales: for example, the short-term food production objective as opposed to the longer-term resource conservation objective. Increasing AE is the objective we highlight in this paper, but to understand farmers' decision making, farmers' objectives, the trade-offs between them, and the timescales at which they operate are essential as well. For example, farmers who are able to invest in fertilizers and want to maximize income might apply nutrients in quantities that result in reduced $\mathrm{AE}$, although the extent of this reduction depends on the fertilizer: grain price ratios (Fig. 7). Likewise, lowresource-endowed farmers might operate within the range of maximum agronomic efficiency - in other words, the linear part of the yield to $\mathrm{N}$ input curve, because of lack of capital assets to invest in fertilizers. However, although efficient, they still make less money than households that can afford to apply higher fertilizer rates. Hence, if the costs of nutrients lost to the environment are not accounted for, as in the gross margin calculations of Fig. 7, higher investment opportunities might result in lower AEs. From this it is clear that the farm scale is the appropriate scale of analysis to understand the important interplay of various objectives affecting the adoption of ISFM interventions.

In conclusion, although the complexity of soil fertility gradients across the landscape and within farms might seem bewildering, it can be reduced to more easily understood concepts as presented in Fig. 2. Adjusting fertilizer and organic matter applications to this variability has the potential to increase fertilizer nutrient AE at farm scale compared to blanket recommendations, in particular where fertility gradients are strong. Important to note is that fertilizer application rates to maximize income are not similar to those maximizing $\mathrm{AE}$ for commonly occurring fertilizer : grain price ratios.

\section{Moving knowledge on local adaptation to the smallholder farmer}

The large spatio-temporal heterogeneity in climate, soil, and socio-economic conditions in smallholder farming systems in SSA presents major challenges for developing local adaptation recommendations. A better understanding of the influence of biophysical and socio-economic factors on the performance of technologies at different scales is necessary to improve targeting of such recommendations.

\subsection{Local adaptation and scale issues}

Past efforts to develop recommendations for ISFM interventions have mostly targeted regions within countries, with tar- get zones mostly defined by broad agro-ecological conditions, thus negating the importance of local adaptation for technology performance. Simplification of recommendations based on the performance of single technologies at plot scale led to development of blanket recommendations that implicitly assume homogeneity of production factors at the landscape, community, and farm level. Results from regionalscale analysis have been valuable in informing policy on urgent need to support farmers to access improved seed and fertilizers to resolve soil fertility challenges underlying low crop productivity (e.g. increase fertilizer use to support crop production intensification, which led to the target of increasing fertilizer use in SSA to $50 \mathrm{~kg}$ nutrients ha ${ }^{-1}$ ). Despite a number of cases of successful large-scale dissemination of ISFM technologies, many ISFM technologies have produced limited impact due to poor match between technologies developed at plot scale to the complex socio-economic and biophysical variability that typify smallholder farms (Giller et al., 2006). Effective large-scale dissemination of ISFM technologies would require not only appropriate recommendations for the use of fertilizer, manure, and improved varieties but also adaptation of technologies for site-specific biophysical and socio-economic conditions that determine technological performance and feasibility, as conceptualized by the local adaptation component of ISFM.

Refining the scale for targeting ISFM recommendations from the regional scale to landscape/village scale and specific farms and fields is inevitably associated with increasing complexity of the research and data requirements, which presents challenges for developing and disseminating "best-fit" ISFM technologies that are appropriate for local adaptation. While field-specific soil fertility conditions would be the ideal target for specific ISFM recommendations, large-scale recommendations targeting specific fields within farms are not feasible due to the characteristic short-range soil fertility variability and the need for high-resolution maps that adequately capture soil fertility differences at scales less than $100 \mathrm{~m}$. Many studies have identified the farm scale as an important unit for targeting ISFM recommendations. Despite the complexity of smallholder farming systems, farm typology studies have shown repeating patterns of farm-scale variability associated with access and management of nutrient resources, farm sizes, and production objectives (see above). This provides opportunities for targeting technologies to farmer typologies or resource groups, and to "field types" within farms to optimize returns to scarce cash, nutrient, and labour resources. 


\subsection{Decision support tools as a research platform}

The variable and complex biophysical and socio-economic conditions in smallholder farming systems in SSA dictate the need for decision support tools (DSTs) to improve understanding of crop-soil processes in time and space and provide insight into the suitability of technological options (Giller et al., 2006). Such tools provide a cost-effective and timesaving approach to improve the diagnosis of constraints and opportunities in agricultural systems, the identification of options for alternative management, and analysing niches for scaling out (Bontkes and Wopereis, 2003). Important DSTs that have significantly advanced understanding of characteristics and functioning of smallholder farming systems in SSA and the suitability of ISFM technologies include the DST to monitor nutrient balances at different spatial scales (NUTMON), various crop-soil simulation models, platforms for integrating modelling tools at farm scale, and the $\mathrm{Nu}$ trient Use in Animal and Cropping systems - Efficiencies and Scales (NUANCES) framework, which focuses on farmscale processes affecting feasibility and impact of ISFM options (Giller et al., 2006).

The NUTMON DST has been widely used in SSA to assess the effects of current farmer management practices and alternative resource management options on nutrient balances (Smaling and Fresco, 1993). Participatory research techniques such as resource flow mapping, matrix ranking, and trend analysis are used to obtain the perspective of farmers. Next to this, a quantitative analysis is carried out which generates indicators such as nutrient flows, nutrient balances, cash flows, gross margins, and farm income. Qualitative and quantitative analyses are then used to improve or design new technologies which tackle soil fertility management problems and which can help to increase the agronomic and economic performance of the farm. The NUTMON framework or its components have been implemented in research and development projects addressing soil fertility management across SSA (e.g. Zingore et al., 2007b) and have aided in an improved understanding of soil fertility variability and farmers' resource use strategies. Results from the various studies using NUTMON have not only shown large negative nutrient balances but have also highlighted strong variation among farmers. Nutrient balances were invariably negative on farms where large areas were used for production of cereal crops for home consumption (e.g. Nkonya et al., 2005), while positive balances were observed on mixed farms where farmers used manure (e.g. Onduru et al., 2007) and for high-value cash crops that received large additions of nutrients (e.g. De Jager et al., 1998). Important considerations for local adaptation of ISFM technologies that have been raised on the basis of the NUTMON approach include erosion control mechanisms to stem important nutrient losses and use of participatory approaches to match technological options to farmers' objectives and socio-economic constraints, including labour.
The development and application of simulation models has aided exploration of the interaction between climatic and nutrient and crop management practices under smallholder farm conditions (Whitbread et al., 2010). Inter- and intra-seasonal rainfall variability is a major challenge for sustaining high crop productivity, with increasing occurrence of mid-season droughts, hence the important need for the development of flexible ISFM technologies that optimize crop productivity in good seasons and minimize losses in poor seasons. The Agricultural Production Systems sIMulator (APSIM) model has been widely applied to explore management strategies to minimize the climate risk associated with $\mathrm{N}$ fertilizer use by smallholder farmers (Whitbread et al., 20010). The model also proved useful in facilitating interactions between researchers and farmers in assessing fertilizer management strategies and effects of trade-offs between fertilizer and weed management on crop productivity (Dimes et al., 2002).

Despite the contributions of NUTMON and crop-soil models to improve local adaptation of ISFM technologies, there have been limitations in upscaling their application at the farm level to explicitly integrate factors that drive farmers' decision-making processes, including the variable nature of soil fertility within farms, sizes of different plots on the farms, mineral and organic resources available to farmers, and other socio-economic constraints. To address this limitation, Thornton and Herrero (2001) developed a modelling framework that combines crop-soil and livestock models and a farm-level database, allowing integration of soil, crop, livestock, and socio-economic factors such as landholdings, household food sufficiency, and labour in assessing the suitability of technological options for achieving food security and/or market production objectives on farms varying in resource endowment. The strength of integrating component models at the farm level is the analysis of trade-offs between resource use options considering soil fertility, crop productivity, livestock productivity, and the objectives of the household. Zingore et al. (2008) used the integrated modelling approach to assess strategies for improving resource use in integrated crop-livestock systems in sub-humid areas in Kenya and Zimbabwe. The study highlighted the critical role of ISFM in sustainability of smallholder agriculture, as cropping was only sustainable on large farms ( $>0.5$ ha) with cattle and used fertilizer in combination with manure.

The NUANCES framework aims at evaluating the shortand long-term impact of alternative farm-level management practices, with a special focus on trade-offs, using various system-analytical tools, including farm typologies, data mining, participatory experimentation, and modelling. This ultimately leads towards the identification of opportunities and pathways towards the sustainable intensification of smallholder farming systems (Giller et al., 2011). The NUANCES framework provides a step-wise process to describe current production systems and their constraints, explain the consequences of current farmers' decisions on resource alloca- 
tion, explore options for agro-technological improvement for a range of possible future scenarios, and design, together with farmers, new management systems that improve resource use efficiency and agricultural productivity (forming the acronym "DEED"). The NUANCES framework has been used to explore the potential of best-fit technologies and the ways they can be best combined at farm level for wideranging smallholder farming systems in SSA.

\subsection{Moving decision support tools to farming communities}

While the above DSTs were mainly used as a platform for research to improve understanding of the complexity of smallholder farming systems, there is increasing scope for their use in guiding ISFM research to be accessible to farming communities. The International Plant Nutrition Institute has developed the Nutrient Expert (NE) extension support tool, a robust computer-based decision support tool that enables local experts to strategically formulate nutrient management guidelines for a range of crops and cropping systems (Pampolino et al., 2012). NE provides farmers with best nutrient management practices to attain a yield goal that is aligned to a specific location, based on potential yield, attainable yield with best nutrient management, and farmer's production objectives. Beyond recommendations for fertilizer and manure application, NE supports local adaptation by providing guidelines on liming and micronutrient requirements, and matching recommendations to available organic resources and fertilizer types available on the local market. NE also includes a profit analysis component to evaluate the costs and benefits of current and recommended, alternative practices. Lastly, as a learning tool for extension staff, NE adds value in moving from general recommendations to site-specific nutrient recommendations, adapted to production conditions and farmer's objectives that are consistent with the scientific principles of site-specific nutrient management, which promotes the best practices of mineral and organic nutrient resources covering the right source, right rate, right time, and right place of nutrient application (Zingore and Johnston, 2013; Witt et al., 2009).

An example for application of NE to develop site-specific fertilizer recommendations for maize production in western Kenya is presented in Table 7. NE algorithms to determine $\mathrm{N}, \mathrm{P}$, and $\mathrm{K}$ fertilizer requirements under specific field conditions were generated from on-farm multi-location nutrient omission trials data on the relationship between the balanced uptake of nutrients at harvest and grain yield, the soil's nutrient supply potential, and attainable yields, which varied depending on site-specific soil constraints. Under current management, maize yields under farmer management practices ranged from 1.4 to $4.4 \mathrm{tha}^{-1}$ in field types classified as having low to high soil fertility status (Table 7). Agronomic efficiencies of $\mathrm{N}$ under farmer practices were less than $22 \mathrm{~kg}_{\text {grain }} \mathrm{kg}^{-1} \mathrm{~N}$, indicating suboptimal $\mathrm{N}$ responses for the yield range. NE recommendations showed large potential to increase yields under low and medium soil fertility conditions by at least $100 \%$, while concomitantly increasing agronomic $\mathrm{N}$ efficiency to at least $25 \mathrm{~kg}_{\text {grain }} \mathrm{kg}^{-1} \mathrm{~N}$ (Table 7). NE showed a contrasting trend in recommendations for the high-fertility field type by recommending reduction of $\mathrm{N}$ and $\mathrm{P}$ and including $\mathrm{K}$ - fertilizer recommendation targeted at "maintenance and balanced fertilization" in nutrientrich soils. Expected yield increases over current management were small, but high AE was achieved by avoiding oversupply of $\mathrm{N}$ and balanced nutrient application. A broad community of research and development organizations are working together through the African Soil Health Consortium (http://www.cabi.org/ashc/) to translate findings from research on ISFM. A series of handbooks, videos, posters, leaflets, and policy briefs are being produced to support learning on ISFM for farmers, development organizations and at university level (e.g. Wairegi et al., 2014).

\section{Conclusions and key research challenges}

Kofi Annan, the chairman of the board of AGRA, stressed that the African green revolution should be uniquely African by recognizing the continent's great diversity of landscapes, soils, climates, cultures, and economic status, while also learning lessons from earlier green revolutions in Latin America and Asia (Annan, 2008). The local adaptation component of ISFM is aligned to this request and operates at two scales: (i) at plot scale, dealing with alleviating plotspecific constraints to enhanced fertilizer nutrient $\mathrm{AE}$ that are not sufficiently addressed by the introduction of improved germplasm and the application of organic inputs, and (ii) at farm scale, dealing with decision-making processes on allocation of resources (inputs, labour, etc.) within the farm as affected by household production objectives and resource endowments.

At plot level, organic inputs alone, depending on their quality and quantity applied, can only alleviate some of the constraints that inhibit enhanced AE values for fertilizer (Table 1). Integration of other plot-level interventions has the potential to increase fertilizer nutrient $\mathrm{AE}$ values, and some of these interactions are well understood (e.g. the application of SMNs in combination with "standard" fertilizer). The mechanistic basis for other interactions is less well developed. For instance, how do tillage operations affect fertilizer nutrient AE? Reduced tillage with retention of mulch can favour fertilizer AE through enhanced availability of soil moisture, especially under drought stress, but on the other hand, more continuous soil pore systems could favour movement of fertilizer nutrients to the subsoil. Lime application can enhance fertilizer AE by removing exchangeable $\mathrm{Al}$ constraints to crop growth but can change the soil chemistry and the relative availability of plant nutrients other than macronutrients. Furthermore, the diagnosis and rehabilitation, if real- 
Table 7. Maize productivity and $\mathrm{N}$ agronomic efficiency on the basis of fertilizer recommendations generated by Nutrient Expert. Maize yield response functions used to generate improved fertilizer recommendations were based on multi-location nutrient omission trials conducted on farms in different resource groups. Wide-ranging fields were simplified into three categories of soil fertility based on baseline yields and yield response to $\mathrm{N}, \mathrm{P}$, and $\mathrm{K}$ fertilizer application.

\begin{tabular}{llrl}
\hline Soil fertility status & $\begin{array}{l}\text { Fertilizer N:P:K application rate } \\
\mathrm{kg} \mathrm{ha}^{-1}\end{array}$ & $\begin{array}{l}\text { Maize productivity } \\
\mathrm{tha}^{-1}\end{array}$ & $\begin{array}{l}\text { Agronomic efficiency of N* } \\
\mathrm{kggrain} \mathrm{kg} \mathrm{N}^{-1}\end{array}$ \\
\hline Current practice & & & 1.4 \\
\hline Low & $21-3-0$ & 2.2 & 21 \\
Medium & $32-9-0$ & 4.4 & 18 \\
High & $80-58-0$ & & 25 \\
\hline Nutrient Expert recommendation & 3.5 & 30 \\
\hline Low & $100-25-15$ & 4.5 & 40 \\
Medium & $100-40-25$ & 5.0 & \\
High & $50-33-20$ & & \\
\hline
\end{tabular}

* Agronomic efficiency values were determined at variable $\mathrm{P}$ and $\mathrm{K}$ application rates, which may result in underestimation of agronomic $\mathrm{N}$ efficiency values in some cases. It is assumed that $\mathrm{N}$ is the most limiting nutrient and increasing $\mathrm{P}$ and $\mathrm{K}$ application at the rates of $\mathrm{N}$ considered will have small effects on agronomic $\mathrm{N}$ efficiency.

istic in economic and/or agronomic terms, of non-responsive soils is an important research topic, especially in areas where population densities are high with agricultural land in short supply. The impact of enhanced crop uptake of fertilizer on the overall soil fertility status with a specific emphasis on the soil organic $\mathrm{C}$ pool is another topic that requires a better understanding since hypotheses can be formulated in relation to a decline in soil $\mathrm{C}$ due to enhanced nutrient availability or an increase in soil $\mathrm{C}$ due to the higher inputs of organic matter with increased crop productivity.

An important dimension for developing appropriate plotlevel recommendations is the proper diagnosis of soil fertility-related constraints, especially in the context of highly variable soil fertility conditions in African smallholder agriculture. "Traditional" laboratory approaches are costly and time-consuming, and while spectroscopic approaches have demonstrated substantial progress in recent years, ultimately, indirect approaches, e.g. based on local soil fertility evaluation schemes, are likely to be important diagnostic tools.

Mapping secondary and micronutrient deficiencies on a national scale is useful for identifying large areas of likely deficiencies. Recently develop soil mapping approaches used the Africa Soil Information Services (AfSIS) project including compilation of existing soil survey information, data generation using infrared spectrometry, geospatial statistical analysis, and remote sensing have enabled the rapid and costeffective development digital soil maps (http://africasoils. net/). This has offered opportunities to accelerate data collections for accurate diagnosis of soil fertility constraints and improve targeting of technological options. This needs to be followed by omission trials to determine crop-specific response to nutrient combinations and to assess the economics of incorporating secondary and micronutrients into NPK fer- tilizers at both regional and individual farm scales. While for some crops (e.g. maize), substantial efforts have been made to gather above information, other crops (e.g. cassava, bananas, or yams) have not received the attention required to intensify their production.

At farm scale, a better understanding of the interactions between soil fertility conditions, crop and land management practices, and yields as a basis for disentangling the oftenobserved large variability in responses to ISFM practices is necessary in order to develop household- and site-specific recommendations. Allocation of resources within heterogeneous farming communities and farms and its impact on overall farm productivity and resource use efficiency requires attention as does its interactions with household resource endowments and production objectives. Ultimately, local adaptation interventions operate at the interplay of household decision-making processes and soil conditions (within "soilscapes") and can only be fully developed and understood through interdisciplinary approaches, integrating expertise in soil fertility management, socio-economics, and social sciences.

Acknowledgements. IITA wishes to acknowledge the various donors that have supported its natural resource management research for development agenda for the past decades, through which the ISFM agenda was conceptualized and put into action, and, more specifically, the Bill and Melinda Gates Foundation (BMGF), the Directorate General for Development (Belgium), the International Fund for Agricultural Development (IFAD), and the United States Agency for International Development (USAID).

Edited by: N. J. Kuhn 


\section{References}

Abebe, T., Wiersum, K. F., and Bongers, F.: Spatial and temporal variation in crop diversity in agroforestry homegardens of southern Ethiopia, Agroforest. Syst., 78, 309-322, 2010.

Abunyewa, A. A. and Mercer-Quarshie, H.: Response of maize to magnesium and zinc application in the semi-arid zone of West Africa, Asian J. Plant Sci., 3, 1-5, 2004.

Amézquita, E., Thomas, R. J., Rao, I. M., Molina, D. L., and Hoyos, P.: Use of deep-rooted tropical pastures to build-up an arable layer through improved soil properties of an Oxisol in the Eastern Plains (Llanos Orientales) of Colombia, Agric. Ecosyst. Environ., 103, 269-277, 2004.

Annan, K. A.: Forging a Uniquely African Green Revolution, Address by Mr. Kofi A. Annan, Chairman of AGRA, Salzburg Global Seminars, Austria, 30 April 2008.

Baijukya, F. P., de Ridder, N., Masuki, K. F., and Giller, K. E.: Dynamics of banana-based farming systems in Bukoba District, Tanzania: Changes in land use, cropping and cattle keeping, Agric. Ecosyst. Environ., 106, 395-406, 2005.

Barasa, J. N., Omami, E. N., Okalebo, J. R., and Othieno, C. O.: Effect of lime and phophosrus fertilizer applications on performance of French beans in Uasin Gishu district, Kenya, Global J. Biol. Agric. Health Sci., 2, 35-41, 2013.

Bationo, A., Lompo, F., and Koala, S.: Research on nutrient flows and balances in west Africa: state-of-the-art, Agri. Ecosyst. Environ., 71, 19-35, 1998.

Bontkes, T. E. S. and Wopereis, M. C. S. (Eds.): Decision Support Tools for Smallholder Agriculture in Sub-Saharan Africa. A Practical Guide. International Center for Soil Fertility and Agricultural Development (IFDC), Muscle Shoals, AL, USA, and Technical Centre for Agricultural and Rural Cooperation (CTA), Wageningen, The Netherlands, 194 pp., 2003.

Chaudhary, M. R., Gajri, P. R., Prihar, S. S., and Khera, R.: Effect of deep tillage on soil physical properties and maize yields on coarse textured soils, Soil Tillage Res., 6, 31-44, 1985.

Cong, P. T. and Merckx, R.: Improving phosphorus availability in two upland soils of Vietnam using Tithonia diversifolia H., Plant Soil, 269, 11-23, 2005.

Crawford, T. W., Singh Jr., U., and Breman, H.: Solving agricultural problems related to soil acidity in Central Africa's Great Lakes regio, CATALIST project report, IFDC, Alabama,USA, 133 pp., 2008.

de Jager, A., Kariuku, I., Matiri, F. M., Odendo, M., and Wanyama, J. M.: Monitoring nutrient flows and economic performance in African farming systems (NUTMON) - IV. Linking nutrient balances and economic performance in three districts in Kenya, Agric. Ecosyst. Environ., 71, 81-92, 1998.

Dimes, J., Muza, L., Malunga, G., and Snapp, S.: Trade-offs between investments in nitrogen and weeding: On-farm experimentation and simulation analysis in Malawi and Zimbabwe, in: Integrated Approaches to Higher Maize Productivity in the New Millennium: Proceedings of Seventh Eastern and Southern Africa Regional Maize Conference, edited by: Friesen, D. K. and Palmer, A. F. E., 5-11 February, 2002, Nairobi, Kenya: CIMMYT (International Maize and Wheat Improvement Center) and KARI (Kenya Agricultural Research Institute), 2002.
Dixon, J., Gulliver, A., and Gibbon, D.: Farming Systems and Poverty: Improving Farmers' Livelihoods in a Changing World, FAO, Rome, 2001.

Giller, K. E.: Can we define the term 'farming systems'? A question of scale, Outlook Agric., 42, 149-153, 2013.

Giller, K. E., Rowe, E., de Ridder, N., van Keulen, H.: Resource use dynamics and interactions in the tropics: Scaling up in space and time, Agric. Syst., 88, 8-27, 2006.

Giller, K. E., Witter, E., Corbeels, M., and Tittonell, P.: Conservation agriculture and smallholder farming in Africa: The heretics' view, Field Crops Res., 114, 23-34, 2009.

Giller, K. E., Tittonell, P., Rufino, M. C., van Wijk, M. T., Zingore, S., Mapfumo, P., Adjei-Nsiah, S., Herrero, M., Chikowo, R., Corbeels, M., Pacini, C., de Ridder, N., Smith, J., Karanja, S., Quiroz, C., Kungu, J., Baijukya, R., Kaizzi, C., Mwale, M., Nwaga, C., Sanogo, O. M., van de Burg, J., Yeboah, R., Rowe, R., and Vanlauwe, B.: Communicating complexity: Integrated assessment of trade-offs within African farming systems to support development policy, Agric. Syst., 104, 191-203, 2011.

Gudu, S. O., Okalebo J. R., Othieno, C. O., Obura, P. A., Ligeyo, D. O., Shulze, D., and Johnston, C.: Response of five maize genotypes to nitrogen, phosphorus and lime on acidic soils of western Kenya, Afr. Crop Sci. Conference proceedings, 7, 1109-1115, 2005.

Jensen, J. R., Bernhard, R. H., Hansen, S., McDonagh, J., Møberg, J. P., Nielsen, N. E., and Nordbo, E.: Productivity in maize based cropping systems under various soil-water-nutrient management strategies in a semi-arid, alfisol environment in East Africa, Agric. Water Management, 59, 217-237, 2003.

Jones, A., Breuning-Madsen, H. Brossard, M. Dampha, A., Deckers, J., Dewitte, O. Gallali, T., Hallett, S. Jones, R., Kilasara, M. Le Roux, P., Micheli, E., Montanarella, L. Spaaergaarden, O., Thiombiano, L., Van Ranst, E. Yemefack, M., and Zougmoré, R. (Eds.): Soil Atlas of Africa, European Commission, Publications Office of the European Union, Luxembourg, 2013.

Kamanga, B. C. G., Waddington, S. R., Whitbread, A. M., Almekinders, C. J. M., and Giller, K. E.: Improving the efficiency of use of small amounts of nitrogen and phosphorus fertiliser on smallholder maize in central Malawi, Exp. Agric., 50, 229-249, 2014.

Kayombo, B. and Lal, R.: Tillage systems and soil compaction in Africa, Soil Tillage Res., 27, 35-72, 1993.

Legesse, H., Nigussi-Dechassa, R., Gebeyehu, S., Bultosa, G., and Mekbib, F.: Response to soil acidity of common bean genotypes (Phaseolus vulgaris L.) under field conditions at Nedjo, western Ethiopia, Sci. Technol. Arts Res. J., 2, 3-15, 2013.

Lisuma, J. B., Semoka, J. M. R, and Semu, E.: Maize yield response and nutrient uptake after micronutrient application on a volcanic soil, Agron. J., 98, 402-406, 2006.

Mashingaidze, N., Belder, P., Twomlow, S., Hove, L., and Moyo, M.: Improving maize (Zea mays L.) performance in semiarid Zimbabwe through micro-dosing with Ammonium nitrate tablets, Experimental Agric., 49, 179-196, 2013.

Mbakaya, S. D., Okalebo, J. R., Muricho, M., and Lumasayi, S.: Effects of liming and inorganic fertilizers on maize yield in Kakamega north and Ugunja districts, western Kenya, KARI, Nairobi, Kenya, 2011.

Miriti, J. M., Esilaba, A. O., Bationo, A, Cheruiyot, H., Kihumba, J., and Thuranira, E. G.: Tie-riding and integrated nutrient manage- 
ment options for sustainable crop production in semi-arid eastern Kenya, in: Advances in integrated soil fertility management in sub-Saharan Africa: challenges and opportunities, edited by: Bationo, A., Waswa, B., Kihara, J., and Kimetu, J., Springer, Dordrecht, the Netherlands, 435-441, 2007.

Misiko, M., Tittonell, P., Giller, K. E., and Richards, P.: Strengthening understanding and perceptions of mineral fertilizer use among smallholder farmers: evidence from collective trials in western Kenya, Agric. Human Values, 28, 27-38, 2011.

Morton, J. F.: The impact of climate change on smallholder and subsistence agriculture, Proc. Natl. Acad. Sci., 10, 19680-19685, 2007.

Mupangwa, W., Twomlow, S., and Walker, S.: Reduced tillage, mulching and rotational effects on maize (Zea mays L.), cowpea (Vigna unguiculata (Walp) L.) and sorghum (Sorghum bicolor L. (Moench)) yields under semi-arid conditions, Field Crops Res., 132, 139-148, 2012.

Nkonya, E., Pender, J., Kaizzi, C., Edward, K., and Mugarura, S.: Policy options for increasing crop productivity and reducing soil nutrient depletion and poverty in Uganda, Environmental and Production Technology Division Discussion Paper \#138, Washington DC: International Food Policy Research Institute, 2005.

Onduru, D. D., De Jager, A., Muchena, F. N., Gachimbi, L., and Gachini, G. N.: Socioeconomic factors, soil fertility management and cropping practices in mixed farming systems of sub-Saharan Africa: a study in Kiambu, central highlands of Kenya, Int. J. Agric. Res., 2, 426-439, 2007.

Pampolino, M. F., Witt, C., Pasuquin, J. M., and Johnston, A.: Development Approach and Evaluation of the Nutrient Expert Software for Nutrient Management in Cereal Crops, Comp. Electr. Agric., 88, 103-110, 2012.

Paul, B. K., Vanlauwe, B., Ayuke, F., Gassner, A., Hoogmoed, M., Hurisso, T. T., Koala, S., Lelei, D., Ndabamenye, T., Six, J., and Pulleman, M. M.: Medium-term impact of tillage and residue management on soil aggregate stability, soil carbon and crop productivity, Agric. Ecosyst. Environ., 164, 14-22, 2013.

Piha, M. I.: Optimizing fertilizer use and practical rainfall capture in a semi-arid environment with variable rainfall, Exp. Agri., 29, 405-415, 1993.

Pretty, J., Toulmin, C., and Williams, S.: Sustainable intensification in African agriculture, Int. J. Agric. Sustain., 9, 5-24, 2011.

Prudencio, C. F.: Ring management of soils and crops in the West African semi-arid tropics: the case of the Mossi farming system in Burkina Faso, Agric. Ecosyst. Environ., 47, 237-264, 1993.

Rowe, E. C., van Wijk, M. T., de Ridder, N., and Giller, K. E.: Nutrient allocation strategies across a simplified heterogeneous African smallholder farm, Agric. Ecosyst. Environ., 116, 60-71, 2006.

Rusinamhodzi, L., Corbeels, M., van Wijk, M. T., Rufino, M. C., Nyamangara, J., and Giller, K. E.: A meta-analysis of longterm effects of conservation agriculture on maize grain yield under rain-fed conditions, Agron. Sustain. Develop., 31, 657-673, 2011.

Ruthenberg, H.: Farming Systems in the Tropics, 3rd Edn., Clarendon Press, Oxford, UK, 1980.

Sanchez, P. A.: Tropical soil fertility research: Towards the second paradig, in: Transactions of the 15th World Congress of Soil Science, Acapulco, Mexico, Mexican Soil Science Society, Chapingo, Mexico, 65-88, 1994.
Sanginga, N., Dashiell, K., Diels, J., Vanlauwe, B., Lyasse, O., Carsky, R. J., Tarawali, S., Asafo-Adjei, B., Menkir, A., Schulz, S., Singh, B. B., Chikoye, D., Keatinge, D., and Rodomiro, O.: Sustainable resource management coupled to resilient germplasm to provide new intensive cereal-grain legumelivestock systems in the dry savanna, Agric. Ecosyst. Environ., 100, 305-314, 2003.

Schulz, S., Carsk, R. J., and Tarawali, S. A.: Herbaceous legumes: the panacea for West African soil fertility problems?, in: Sustaining soil fertility in West-Africa, edited by: Keatinge, J. D. H., Breman, H., Manyong, V. M., Vanlauwe, B., and Wendt, J., SSSA Special Publication Number 58, Madison, USA, 157-178, 2001.

Smaling, E. M. A. and Fresco, L. O.: A decision-support model for monitoring nutrient balances under agricultural land use (NUTMON), Geoderma, 60, 235-256, 1993.

Tabo, R., Bationo, A., Gerard, B., Ndjeunga, J, Marchal, D., Amadou, B., Annou, G., Sogodogo, D., Taonda, J. B. S., Hassane O., Maimouna K. Diallo and Koala, S.: Improving cereal productivity and farmers' income using a strategic application of fertilizers in West Africa, in: Advances in integrated soil fertility management in sub-Saharan Africa: Challenges and opportunities, edited by: Bationo, A., Waswa, B., Kihara, J., and Kimetu, J., Kluwer Publishers, The Netherlands, 201-208, 2007.

The, C., Calba, H., Zonkeng, C., Ngonkeu, E. L. M., Adetimirin, V. O., Mafouasson, H. A., Meka, S. S., and Horst, W. J.: Responses of maize grain yield to changes in acid soil characteristics after soil amendments, Plant Soil, 284, 45-57, 2006.

Thierfelder, C., Mombeyarara, T., Mango, N., and Rusinamhodzi, L.: Integration of conservation agriculture in smallholder farming systems of southern Africa: identification of key entry points, Int. J. Agric. Sustain., 11, 317-330, 2013.

Thornton, P. K. and Herrero, M.: Integrated crop-livestock simulation models for scenario analysis and impact assessment. Agric. Syst., 104, 191-203, 2001.

Tilahun, H., Teklu, E., Michael, M., Fitsum, H., and Awulachew, S. B.: Comparative performance of irrigated and rainfed agriculture in Ethiopia, World Appl. Sci. J., 14, 235-244, 2011.

Tittonell, P., Vanlauwe, B., Leffelaar, P. A., Rowe, E. C., and Giller, K. E.: Exploring diversity in soil fertility management of smallholder farms in western Kenya - I. Heterogeneity at region and farm scale, Agric. Ecosyst. Environ., 110, 149-165, 2005.

Tittonell, P., Vanlauwe, B., de Ridder, N., and Giller, K. E.: Heterogeneity of crop productivity and resource use efficiency within smallholder Kenyan farms: Soil fertility gradients or management intensity gradients?, Agric. Syst., 94, 376-390, 2007a.

Tittonell, P., van Wijk, M. T., Rufino, M. C., Vrugt, J. A., and Giller, K. E.: Analysing trade-offs in resource and labour allocation by smallholder farmers using inverse modelling techniques: A casestudy from Kakamega district, western Kenya, Agric. Syst., 95, 76-95, 2007b.

Tittonell, P., Muriuki, A., Shepherd, K. D., Mugendi, D., Kaizzi, K. C., Okeyo, J., Verchot, L., Coe, R., and Vanlauwe, B.: The diversity of rural livelihoods and their influence on soil fertility in agricultural systems of East Africa - A typology of smallholder farms, Agric. Syst., 103, 83-97, 2010.

Tittonell, P. and Giller, K. E.: When yield gaps are poverty traps: The paradigm of ecological intensification in African smallholder agriculture, Field Crop Res., 143, 76-90, 2013. 
Uchida, R. and Hue, N. V.: Soil acidity and liming, in: plant nutrient management in Hawai's soils, approaches for tropical and subtropical agriculture, College of Tropical Agriculture and human resources, university of Hawaii, Manoa, 101-111, 2000.

Vanlauwe, B. and Giller, K. E.: Popular myths around soil fertility management in sub-Saharan Africa, Agric. Ecosyst. Envir., 116, 34-46, 2006.

Vanlauwe, B., Wendt, J., and Diels, J.: Combined application of organic matter and fertilizer, in: Sustaining Soil Fertility in WestAfrica, edited by: Tian, G., Ishida, F., and Keatinge, J. D. H., SSSA Special Publication Number 58, Madison, USA, 247-280, 2001.

Vanlauwe, B., Aihou, K., Tossah, B. K., Diels, J., Sanginga, N., and Merckx, R.: Senna siamea trees recycle Ca from a Ca-rich subsoil and increase the topsoil $\mathrm{pH}$ in agroforestry systems in the West African derived savanna zone, Plant Soil, 269, 285-296, 2005.

Vanlauwe, B., Tittonell, P., and Mukulama, J.: Within-farm soil fertility gradients affect response of maize to fertiliser application in western Kenya, Nut. Cycl. Agroecosyst., 76, 171-182, 2006.

Vanlauwe, B., Bationo, A., Chianu, J., Giller, K. E., Merckx, R., Mokwunye, U., Ohiokpehai, O., Pypers, P., Tabo, R., Shepherd, K., Smaling, E. M. A., and Woomer, P. L.: Integrated soil fertility management: Operational definition and consequences for implementation and dissemination, Outlook Agric., 39, 17-24, 2010.

Vanlauwe, B., Kihara, J., Chivenge, P., Pypers, P., Coe, R., and Six, J.: Agronomic use efficiency of $\mathrm{N}$ fertilizer in maize-based systems in sub-Saharan Africa within the context of integrated soil fertility management, Plant Soil, 339, 35-50, 2011.

Vanlauwe, B., Coyne, D., Gockowski, J., Hauser, S., Huising, J., Masso, C., Nziguheba, G., and Van Asten, P.: Sustainable intensification and the smallholder African farmer, Curr. Op. Envir. Sust., 8, 15-22, 2014a.

Vanlauwe, B., Wendt, J., Giller, K. E., Corbeels, M., Gerard, B., and Nolte, C.: A fourth principle is required to define 1 Conservation Agriculture in sub-Saharan Africa: the appropriate use of fertilizer to enhance crop productivity, Field Crop Res., 155, 10-13, 2014b.

Von Uexkull, H. R.: Efficient fertilizer use in acid upland soils of the humid tropics, Fertilizer and Plant Nutrition bulletin 10, FAO, Rome, 59 pp., 1986.
Wairegi, L. W. I., van Asten, P. J. A., Giller, K. E., and Fairhurst, T. H.: African Soil Health Consortium: Banana-Coffee System Cropping Guide (CABI, Nairobi), 2014.

Weil, R. R. and Mughogho, S. K.: Sulfur nutrition in maize in four regions of Malawi, Soil Sci. Soc. Am. J., 92, 649-656, 2000.

Wendt, J. W. and Rijpma, J.: Sulphur, zinc, and boron deficiencies in the Dedza Hills and Thiwi-Lifidzi regions in Malawi, Trop. Agric., 74, 81-89, 1997.

Whitbread, A., Robertson, M., Carberry, P., and Dimes, J.: How farming systems simulation can aid the development of more sustainable smallholder farming systems in Southern Africa, Eur. J. Agr., 32, 51-58, 2010.

Witt, C., Pasuquin, J. M. C. A., Pampolino, M. F., Buresh, R. J., and Dobermann, A.: A manual for the development and participatory evaluation of site-specific nutrient management for maize in tropical, favorable environments, International Plant Nutrition Institute: Penang, Malaysia, 2009.

Zingore, S. and Johnston, A.: The 4R Nutrient Stewardship in the context of smallholder Agriculture in Africa, in: Agro-ecological Intensification of Farming Systems in the East and Central African Highlands, edited by: Vanlauwe, B., Blomme, G., and Van Asten, P., Earthscan, UK, 77-84, 2013.

Zingore, S., Murwira, H. K., Delve, R. J., and Giller, K. E.: Influence of nutrient management strategies on variability of soil fertility, crop yields and nutrient balances on smallholder farms in Zimbabwe, Agric. Ecosyst. Environ., 119, 112-126, 2007a.

Zingore, S., Murwira, H. K., Delve, R. J., and Giller, K. E.: Soil type, historical management and current resource allocation: three dimensions regulating variability of maize yields and nutrient use efficiencies on African smallholder farms, Field Crop Res., 101, 296-305, 2007b.

Zingore, S., Delve, R. J., Nyamangara, J., and Giller, K. E.: Multiple benefits of manure: The key to maintenance of soil fertility and restoration of depleted sandy soils on African smallholder farms, Nut. Cycl. Agroecosyst., 80, 267-282, 2008.

Zingore, S., Tittonell, P., Corbeels, M., Van Wijk, M. T., and Giller, K. E.: Managing soil fertility diversity to enhance resource use efficiencies in smallholder farming systems: a case from Murewa District, Zimbabwe, Nutr. Cycl. Agroecosys., 90, 87-103, 2011. 